\title{
Advanced technological tools to study multidrug resistance in cancer
}

\author{
Luca Andrei $^{\mathrm{a}, \mathrm{b}}$, Sandor Kasas ${ }^{\mathrm{c}, \mathrm{d}}$, Ignacio Ochoa Garrido ${ }^{\mathrm{e}, \mathrm{f}, \mathrm{g}}$, Tijana Stankovićc ${ }^{\mathrm{h}}$, \\ Mónica Suárez Korsnes ${ }^{\mathrm{i}, \mathrm{j}}$, Radka Vaclavikova ${ }^{\mathrm{k}, 1}$, Yehuda G. Assaraf ${ }^{\mathrm{m}}$, Milica Pešic , $^{\mathrm{h}, *}$ \\ a Department of Pneumology, University of Medicine and Pharmacy "Grigore T. Popa" Iasi, Romania \\ ${ }^{\mathrm{b}}$ Advanced Center for Research and Development in Experimental Medicine (CEMEX), University of Medicine and Pharmacy "Grigore T. Popa” Iasi, Romania \\ ${ }^{\mathrm{c}}$ Laboratoire de Physique de la Matière Vivante, EPFL, Lausanne, Switzerland \\ d Plateforme de Morphologie UFAM, CUMRL, University of Lausanne, Lausanne, Switzerland \\ ${ }^{\mathrm{e}}$ Group of Applied Mechanics and Bioengineering (AMB), Aragón Institute of Engineering Research (I3A), University of Zaragoza, Zaragoza, Aragon 50018, Spain \\ ${ }^{\mathrm{f}}$ Centro Investigación Biomédica en Red. Bioingenieria, biomateriales y nanomedicina (CIBER-BBN), Zaragoza, Aragon 50018, Spain \\ ${ }^{\mathrm{g}}$ Tissue Microenvironment Lab (TME). Institute for Health Research Aragon (IIS Aragón), Instituto de Salud Carlos III, Madrid, 28029, Spain \\ ${ }^{\mathrm{h}}$ Institute for Biological Research "Siniša Stanković"- National Institute of Republic of Serbia, University of Belgrade, Despota Stefana 142, 11060 Belgrade, Serbia \\ ${ }^{\mathrm{i}}$ Department of Chemistry, Biotechnology and Food Science, Norwegian University of Life Sciences (NMBU), Ås, Norway \\ ${ }^{\mathrm{j}}$ Korsnes Biocomputing (KoBio), Ås, Norway \\ ${ }^{\mathrm{k}}$ Toxicogenomics Unit, National Institute of Public Health, Prague, Czech Republic \\ ${ }^{1}$ Laboratory of Pharmacogenomics, Biomedical Center, Faculty of Medicine in Pilsen, Charles University, Pilsen, Czech Republic \\ ${ }^{\mathrm{m}}$ The Fred Wyszkowski Cancer Research Laboratory, Department of Biology, Technion-Israel Institute of Technology, Haifa, 3200000, Israel
}

\section{A R T I C L E I N F O}

\section{Keywords:}

Cancer multidrug resistance

Next-generation sequencing

Atomic force microscopy

Single live-cell tracking

3D cultures

Microfluidic devices

\begin{abstract}
A B S T R A C T
The complexity of cancer biology and its clinical manifestation are driven by genetic, epigenetic, transcriptomic, proteomic and metabolomic alterations, supported by genomic instability as well as by environmental conditions and lifestyle factors. Although novel therapeutic modalities are being introduced, efficacious cancer therapy is not achieved due to the frequent emergence of distinct mechanisms of multidrug resistance (MDR). Advanced technologies with the potential to identify and characterize cancer MDR could aid in selecting the most efficacious therapeutic regimens and prevent inappropriate treatments of cancer patients. Herein, we aim to present technological tools that will enhance our ability to surmount drug resistance in cancer in the upcoming decade. Some of these tools are already in practice such as next-generation sequencing. Identification of genes and different types of RNAs contributing to the MDR phenotype, as well as their molecular targets, are of paramount importance for the development of new therapeutic strategies aimed to enhance drug response in resistant tumors. Other techniques known for many decades are in the process of adaptation and improvement to study cancer cells' characteristics and biological behavior including atomic force microscopy (AFM) and live-cell imaging. AFM can monitor in real-time single molecules or molecular complexes as well as structural alterations occurring in cancer cells induced upon treatment with various antitumor agents. Cell tracking methodologies and software tools recently progressed towards quantitative analysis of the spatio-temporal dynamics of heterogeneous cancer cell populations and enabled direct monitoring of cells and their descendants in 3D cultures. Besides, novel 3D systems with the advanced mimicking of the in vivo tumor microenvironment are applicable to study different cancer biology phenotypes, particularly drug-resistant and aggressive ones. They are also suitable for investigating new anticancer treatment modalities. The ultimate goal of using phenotype-driven 3D cultures for the investigation of patient biopsies as the most appropriate in vivo mimicking model, can be achieved in the near future.
\end{abstract}

\section{Introduction}

Cancers comprise various cell populations with distinct phenotypic and genotypic profiles as well as with an inherent potential for metastasis (Marusyk and Polyak, 2010). A recent definition describes cancers as epigenetic disorders where cells emerge and compete under a robust evolutionary pressure (Vitale et al., 2019). The extracellular environment can produce a positive selection of subsets of pre-malignant cells with a fitness advantage towards metastasis and colonization of healthy tissues (Martincorena et al., 2017; Ostrow et al., 2014).

\footnotetext{
* Corresponding author.

E-mail address: camala@ibiss.bg.ac.rs (M. Pešić).
} 
Heterogeneity leads to the expansion of diverse niches, including hypoxic or perivascular regions that might support the development of cancer stem cell phenotypes and drug-resistant cell populations (Fu et al., 2015; Junttila and de Sauvage, 2013; Mao et al., 2013; McGranahan and Swanton, 2017; Tellez-Gabriel et al., 2016).

Cancer multidrug resistance (MDR) has been a subject of intensive research in the past four decades in an attempt to decipher the molecular mechanisms underlying MDR and develop novel modalities to surmount this major therapeutic impediment (Cui et al., 2018; Li et al., 2016b; Livney and Assaraf, 2013; Robey et al., 2018; Zhitomirsky and Assaraf, 2016). Still, the implementation of the significant amount of the generated findings in this field into clinical practice is rather insufficient. New emerging tools are necessary to address many burning questions regarding cancer MDR. Characterization of different MDR phenotypes (Assaraf and Borgnia, 1994; Goler-Baron et al., 2012; GolerBaron and Assaraf, 2011; Ifergan et al., 2005; Zhitomirsky and Assaraf, 2017, 2015), correlation of their presence with cancer aggressive behavior and identification of new druggable targets to overcome MDR, are some of many important tasks in studying cancer MDR.

Cancer is a complex disease that systematically affects the whole organism. Characteristics of cancer cells and their tumor microenvironment (TME) favor the progression of the disease and invasion of remote organs, distinct from the primary location of the cancer. These characteristics or hallmarks of cancer have been described and revised by Hanahan and Weinberg (Hanahan and Weinberg, 2011, 2000). In its latest revision, 10 characteristics of cancer were identified that are hard to study with classical two-dimensional (2D) cell culture methodology.

Cell-culture based screening of anticancer drug effects has significantly evolved in the past decades. For a long time, conventional 2D cell cultures have been employed as the sole in vitro model to test the anticancer activity of new drugs. In this respect, the NCI-60 human tumor cell lines screen using a panel of 60 human tumor cell lines of distinct cell lineage was introduced by the National Cancer Institute in Bethesda, MD, USA. These cytotoxicity studies on cells grown under monolayer conditions are quite affordable and easy to perform but have great disadvantages. Generally, these simple in vitro 2D models are unable to mimic the complexity of the tumor tissue and therefore their cytotoxicity results are rather different from those obtained in vivo (Pampaloni et al., 2007).

Animal models are important to study complex interactions with surrounding cells and tissues in cancer research. However, animal models including patient-derived xenografts, are far away from genuine tumors in cancer patients. Therefore, complementary methods capable of creating a complex in vitro microenvironment using microfluidic technology, have emerged. Three-dimensional (3D) cell cultures were introduced in anticancer drug screening to gain more valid in vitro data that could more faithfully represent the in vivo results of drug sensitivity. 3D culturing of human cells hence mimicking the conditions of the genuine tumors can surpass both practical and ethical obstacles in using animal models. Spheroids are the simplest 3D cell culture models that mimic cell-to-cell interactions and hypoxic conditions and therefore provide a more realistic drug response than conventional 2D cultures (Costa et al., 2016). However, spheroids still have some limitations primarily including the lack of extracellular matrix (ECM), with its complex physical and chemical characteristics (Valente et al., 2017). For that reason, various scaffold-based 3D cell cultures were developed in recent years. They represent biocompatible 3D networks designed to provide structural support to the cells, with physicochemical characteristics that resemble ECM present in genuine tumor tissue (HoarauVéchot et al., 2018). Although these are more advanced 3D cultures, they are characterized by static conditions and lack fluid interstitial flow (i.e. blood) that is normally present in any tissue which significantly affects various phenotypes including response to cytotoxic drugs.

Other tools like next-generation sequencing (NGS) which has become irreplaceable in discovering mutations, gene expression and cancer biomarkers, offers a broad spectrum of possibilities for studying MDR (Chandana et al., 2019; Cho et al., 2019; Kyrochristos et al., 2019; Li et al., 2015a, 2015b). In the last years, high throughput NGS technology revealed important findings regarding the genomic, epigenetic and transcriptomic diversity of cancers that otherwise would not be possible to acquire by standard histopathological analysis (Jiang et al., 2014; Teixeira et al., 2019; Turajlic et al., 2019). This is of paramount importance and clinical relevance especially for cancers displaying high levels of drug resistance (Røe et al., 2012).

Some less common techniques such as atomic force microscopy (AFM) and single live-cell imaging can facilitate the identification of MDR phenotypes in cancer patients' specimens. AFM is a very versatile tool for biological research. Its multispectral capacity to monitor the topographical, mechanical adhesive and oscillatory patterns of living cells makes the instrument highly promising for cancer research and more specifically for drug development (Prusty et al., 2018). On the other hand, the analysis performed by tracking single cells in a heterogeneous cancer cell population can determine the fate of each cancer cell while studying different characteristics including proliferative capacity, motility, shape, size, signaling patterns, and intercellular communication.

In this review we discuss the potential of i) NGS application in identification of cancer MDR as well as research covering DNA-based sequencing, RNA-based sequencing and clinical applications of NGS; ii) AFM application in cancer research and anticancer drug screening; iii) Single live-cell imaging applicability for the identification of drug-resistant and aggressive clones of malignant cells; iv) The use of microfluidics-based 3D cell cultures to evaluate cancer characteristics and complex interactions with its surrounding including blood flow as well as, v) Anticancer drug efficacy and mechanisms of resistance emerging under selective conditions that mimic the genuine tumor.

\section{Next-generation sequencing (NGS) in cancer MDR research}

The rapid development of sequencing technologies for the human genome and transcriptome analysis has led to an enormous increase in our knowledge regarding the roles of genetic variability in various disorders including cancer. NGS technologies are useful in a broad spectrum of applications in biomedical research. These include a variant discovery by whole-genome sequencing (WGS), whole-exome sequencing (WES) (Hitomi and Tokunaga, 2017) or targeted sequencing of genomic regions or gene panels of interest (Hlavac et al., 2018; Soukupova et al., 2018; Wakai et al., 2019). RNA sequencing (RNA-seq) offers sequencing of the entire transcriptome and chromatin immunoprecipitation with sequencing (ChIP-seq) enables investigation of the epigenetic architecture of the genome (Rabbani et al., 2016). Other NGS applications include de novo assemblies of bacterial and eukaryotic genomes, species classification and/or gene discovery through metagenomics and DNA-Protein interaction analyses (Metzker, 2010; Precone et al., 2015).

Regarding MDR, NGS technologies allow us to identify DNA- and RNA-based molecular profiles associated with tumor development, progression and therapy outcome and thus recognize genetic determinants of MDR phenomenon in solid tumors (Chandana et al., 2019; Gov et al., 2017; Kyrochristos et al., 2019; Verma and Sharma, 2018) and leukemia (Albitar et al., 2017; Bereza et al., 2017; Szankasi et al., 2016). On the basis of ultra-deep sequencing, it is also possible to understand and combat the antibiotic resistome (Crofts et al., 2017; Hadjadj et al., 2019) and characterize in detail, drug resistance-associated mutations in pathogens and viruses causing serious diseases (Alidjinou et al., 2017; Gautam et al., 2019; Parker and Chen, 2017; Ramanathan et al., 2017; Soares et al., 2019; Thomson et al., 2016) as summarized in Fig. 1. 


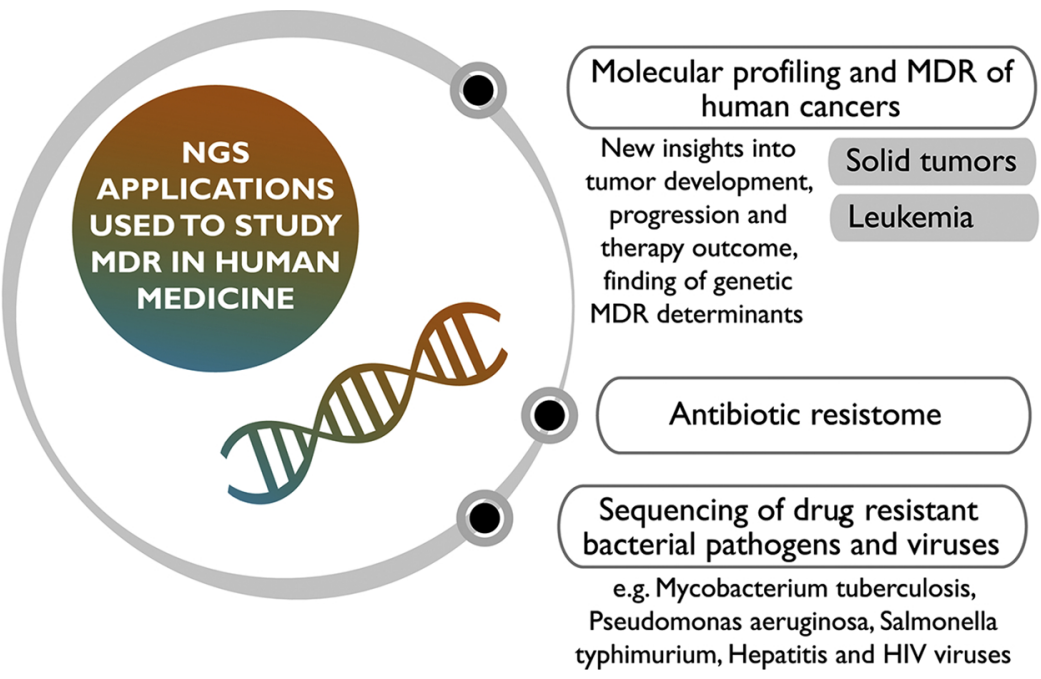

Fig. 1. Application of NGS in studying MDR.

\subsection{DNA sequencing}

DNA sequencing opens new avenues in the study of tumor aggressiveness, allows comparative analyses between different population characteristic mutation rates (Saidijam et al., 2015), evaluation of DNA damage response and repair or telomere modification attributed to chemo- and radio-resistance (Nahar et al., 2018; Røe et al., 2012). The development of chemoresistance can arise due to either single or multiple drug applications. Sequencing or copy number analysis showed that the administration of multi-agent regimens leads to the development of MDR, which appears to be pathway-specific and not dependent on the combinations of mutations (Hammond et al., 2016; Pritchard et al., 2012). In addition, it is well established that drug resistance can be induced also after targeted therapies, and therefore the necessity for a change in clinical oncology treatment strategies is emerging (Masoud and Pagès, 2017; Pritchard et al., 2012). Chemoresistance can be attributed to cancer cells with polyploidy, stemness phenotype or proinflammatory secretory phenotype as revealed by analysis of cDNA and mitochondrial DNA (mtDNA) (Ma et al., 2015; Rohnalter et al., 2015).

DNA repair is an important mechanism in the development of drug resistance along with chromosomal aberrations, gene amplification, and genomic deletions. Moreover, a direct association between DNA methylation and MDR has been established (Chen et al., 2015; Kadioglu et al., 2016). DNA methylation status is gaining increased importance in the diagnosis of cancers since DNA methylation status can be examined in serum, urine or sputum of patients with neoplastic or pre-neoplastic lesions (Worm and Guldberg, 2002).

Complete genome sequencing helps in the identification of genes that contribute to MDR and consequently facilitates the decision as to which therapeutic regimen the patient will benefit the most (Hearn et al., 2018; Schröder et al., 2012). Thus, identification of co-mutations such as BRAF and NRAS supports the clinical practice which uses combinational therapy to target different pathways (Raaijmakers et al., 2016). Both DNA and RNA assays remain the basic methods through which the recurrent mutations are identified in most cancer types. However, combinations of epigenomic or genomic markers combined with proteomic biomarkers increase the therapeutic success rate, rather than utilizing just a single approach (Sinha et al., 2019). An example of multi-omics approach, is the combination of proteomics, transcriptomics and DNA interactome analyses which revealed a valuable information about mutant $\mathrm{p} 53$ proteins that have been discovered in more than $50 \%$ of human malignancies (Walerych et al., 2016), while the role of the mutated TP53 gene in drug resistance is still speculative (Alzoubi et al., 2016).

Importantly, some mutations can have a detection rate of up to
$73 \%$, when the tests are combined from different sources: circulating tumor DNA (ctDNA), biopsy and circulating tumor cells (CTC). Although differences between CTC and ctDNA genotyping and discordant genotypes between tumor biopsy and blood-based analyses were recognized, these disagreements are due to the methodological differences in isolation (Schechter et al., 2015; Sundaresan et al., 2016). Thus, it is known that the DNA isolation for a liquid biopsy varies due to tumor-specific mutations in DNA isolated from other cells present in the urine or the fluid itself (Mikhaylenko et al., 2018).

\subsection{RNA sequencing}

RNA sequencing (RNA-Seq) technologies have been developed to analyze whole transcriptome profiles including gene expression profiles of protein-coding mRNA as well as non-coding RNAs such as microRNA (miRNA), long non-coding RNA (lncRNA) and circular RNA (circRNA) profiles (Costa et al., 2013; Ng et al., 2018; Nigita et al., 2019; Wang et al., 2009b). This technology has advanced predominantly in the last two years and it gradually replaces whole transcriptome arrays.

In MDR research, RNA sequencing facilitates the identification of transcriptional-based markers of acquired resistance, cancer progression, and treatment response (Li et al., 2015a; Wang et al., 2019a; Xi et al., 2017). Besides, RNA sequencing can be used to study associations between genomic and transcriptomic alterations during tumor development, drug response and clinical outcome of patients. These changes can be associated with the development of drug resistance and differences in therapy outcomes (Cho et al., 2019). Whole transcriptome RNA sequencing can reveal the role of transcript deregulation and alternative splicing in malignant transformation and chemoresistance (De Laere et al., 2017; Goff et al., 2013) as described in Table 1. RNAs devoid of coding potential referred to as non-coding RNAs (ncRNAs) have a great impact on molecular mechanisms, ranging from developmental processes to various diseases including cancer (Beermann et al., 2016; Tomar et al., 2019). ncRNAs are divided into two subclasses according to a relatively broad size threshold -miRNAs and lncRNA.

Small non-coding RNAs called microRNAs (miRNAs) are indeed approximately $21-23$ bp long RNAs, which are involved in tumor development, progression and drug resistance through regulation of gene expression. Particular miRNAs such as miR-199a-5p and miR-222 were found to be associated with MDR of human colorectal cancer (Kong et al., 2012; Xu et al., 2012), while miR-27b modulates chemosensitivity of gastric cancer cells (Fang et al., 2016). The majority of miRNA profile studies were performed using microarrays. The recent development of RNA sequencing revealed new miRNAs (miR-7-5p, miR-22$3 p$, miR-483-3p) the gene targets of which were correlated with drug 
Table 1

Examples of using RNA sequencing technology in identification of MDR phenotype in human cancer.

\begin{tabular}{|c|c|c|}
\hline RNA & RNA sequencing technology & Effects and clinical applications \\
\hline \multicolumn{3}{|c|}{ Coding RNA; } \\
\hline & $\begin{array}{l}\text { Targeted RNA sequencing of Androgen receptor (AR) in liquid } \\
\text { biopsies }(\mathrm{n}=34 \text { ) from } 30 \text { patients with castration-resistant } \\
\text { prostate cancer }\end{array}$ & $\begin{array}{l}\text { Comprehensive AR profiling revealed associations of } A R \text { alterations } \\
\text { with endocrine treatment outcome in patients with castration- } \\
\text { resistant prostate cancer }\end{array}$ \\
\hline & $\begin{array}{l}\text { RNA sequencing in patients with colorectal cancer }(n=35) \text { and } \\
\text { multi-organ metastases }\end{array}$ & $\begin{array}{l}\text { Alterations in gene expression profiles during tumor metastatic } \\
\text { development are associated with development of MDR and } \\
\text { therapeutic outcome in colorectal cancer }\end{array}$ \\
\hline & $\begin{array}{l}\text { RNA sequencing of MCF-7 and MCF-7/MDR breast cancer cell } \\
\text { lines }\end{array}$ & $\begin{array}{l}\text { Analysis and identification of differentially expressed genes and } \\
\text { associated signaling pathways involved in development of } \\
\text { resistance in sensitive MCF-7 and MCF-7/MDR breast cancer cells } \\
\text { (e.g. NOS3 and BDNF genes) }\end{array}$ \\
\hline & $\begin{array}{l}\text { RNA sequencing of CCRF-CEM and resistant CEM/ADR5000 } \\
\text { leukemia cell lines }\end{array}$ & $\begin{array}{l}\text { Except well-known MDR associated genes such as ABCB1, many new } \\
\text { genes were found to be differentially regulated in } \boldsymbol{M D R} \text { cells } \\
\text { (ABCG2, ABCA2, Apoptosis genes, Transcription factor genes, Heat } \\
\text { shock genes, Kinase genes, Receptor genes, Oxidative stress genes) }\end{array}$ \\
\hline & $\begin{array}{l}\text { RNA sequencing of gefitinib-sensitive (PC9 and H292) and } \\
\text { gefitinib-resistant (PC9/GR and H292/GR) non-small cell lung } \\
\text { cancer cell lines }\end{array}$ & $\begin{array}{l}\text { Gene expression profile of } 48 \text { human } \mathrm{ABC} \text { transporters in gefitinib- } \\
\text { resistant PC9/GR and } \mathrm{H} 292 / \mathrm{GR} \text { cells were examined using RNA-seq } \\
\text { and compared with that of the parental cell lines and ABCC10 was } \\
\text { found to have an important role in acquired resistance to gefitinib } \\
\text { in non-small cell lung cancer }\end{array}$ \\
\hline
\end{tabular}

Reference

Non-coding
RNA;
miRNA

Small RNA sequencing and transcriptome sequencing of oxaliplatin-resistant colorectal cancer cell line HCT116/L and its parental cell line HCT116

IncRNA RNA sequencing data from 456 colorectal tumors compared to normal samples

LncRNA sequencing of the ovarian cancer cell line A2780 and the paclitaxel resistant cell line A2780/PTX

RNA-sequencing at high depth sequencing in primary follicular lymphoma samples ranging from grade 1-3A to aggressive grade $3 B$ variants using unpurified $(n=16)$ and purified $(n=12)$ tumor cell suspensions from nodal samples

circRNA RNA sequencing of cisplatin-sensitive and cisplatin-resistant gastric cancer cells from humans

circRNA expression profiles in normal and malignant esophageal epithelial cell lines by RNA sequencing
miR-22-3p was selected as a target, which promotes bladder cancer resistance by targeting NET1

miR-483-3p was involved in the regulation of oxaliplatin resistance in human colorectal cancer cells through its functional target FAM171B

Potentially oncogenic IncRNA SNHG15 was found to be involved in promoting colon cancer and mediating drug resistance

5 up-regulated and 21 down-regulated lncRNAs are considered as the multidrug-resistant lncRNAs. The multidrug resistant genes $\mathrm{ABCB} 1, \mathrm{ABCB} 4, \mathrm{ABCC} 3$, and ABCG2 are all co-expressed with IncRNA CTD-2589M5.4.

LncRNAs have been differentially expressed across the clinicobiological spectrum of follicular lymphoma with the top deregulated IncRNA called RP4-694A7.2 potentially involved in cell proliferation

Thousands of distinct circRNAs were revealed in cisplatin-sensitive and cisplatin-resistant gastric cancer cells from humans. CircRNA termed circAKT3, was significantly upregulated in cisplatin-resistant gastric cancer tissues and cells. circAKT3 modulated cisplatin sensitivity by sponging miR-198.

813 significantly up- and 445 down-regulated circRNA candidates were found to be associated with pathways involved in metabolism, cell apoptosis, proliferation and migration. Interaction circRNAmiRNA network were constructed.
De Laere et al., 2017

Cho et al., 2019

Yang et al., 2016

Kadioglu et al., 2016

Zhao et al., 2018

Xiao et al., 2018

Liang et al., 2019

Saeinasab et al., 2019 Xu et al., 2018

Roisman et al., 2019

Huang et al., 2019

(Sun et al., 2017)

regulators of miRNAs, transcription, and various protein functions. They can also encode for proteins, as previously reviewed (Hsiao et al., 2017; Yu and Kuo, 2019). The development of next-generation RNA sequencing technologies has allowed scientists to analyze the expression and composition of circRNA and elucidate their roles in pathological processes. CircRNA participates in the regulation of neuronal and cardiovascular diseases as well as in the regulation of cancer progression and drug resistance (Hsiao et al., 2017). Using RNA sequencing, circRNA expression profiles and their changes were identified in cancers including breast, lung, ovarian, endometrial, gastric, pancreatic, colorectal and hepatocellular cancer. Many associations of circRNA expression and circRNA-miRNA networks associated with drug resistance and cancer therapy outcomes, were found (Table 1). In addition, significant deregulation of circRNAs is correlated with drug resistance and therapy outcome of cancer patients. Bioinformatic analyses of circRNA expression identified mainly interactions with miRNA sequences (Chen et al., 2019; Huang et al., 2019). Identification of circRNAs using RNA-seq needs specific bioinformatic tools such as CIRexplorer (Galasso et al., 2016) or miARma-Seq (López-Jiménez et al., 2018) that can detect various associations and junctions of circRNAs with the transcriptome, miRNAs and other noncoding RNAs have been reported. In this respect, Kun-Peng et al., constructed circRNA-miRNA- 


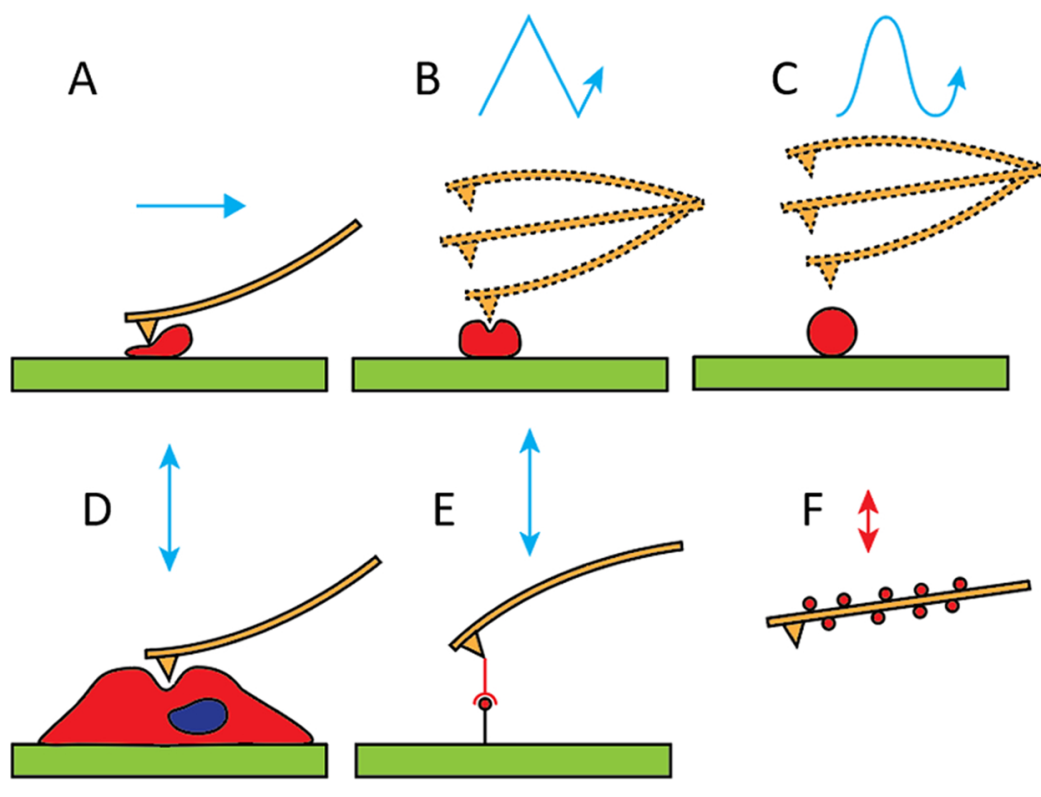

Fig. 2. Different imaging and analysis modes of the AFM. The sample is depicted in red. The arrows indicate the cantilever displacement direction. In blue: control electronics imposed motion. In red: displacement induced by the living organisms present on the cantilever (subfigure F). (A) Contact, (B) Tapping, (C) Noncontact, (D) Force spectroscopy to measure the sample's stiffness, (E) Force spectroscopy to measure molecular interaction forces, and (F) Nanomotion (For interpretation of the references to colour in this figure legend, the reader is referred to the web version of this article).

mRNA pathways related to circRNA hsa_circ_0004674 by TargetScan and miRanda tools (Kun-Peng et al., 2018). Optimal use of RNA-seq data is currently hindered by the short-read nature of the dominant sequencing technologies, which prevents completely reliable reconstruction and quantification of full-length transcripts. Thus, it is necessary to improve the detection of long reads during RNA-seq. This is precisely why direct, amplification-free sequencing of full-length RNA molecules is being introduced with the advent of nanopore sequencing, which raises the possibility of yet another revolution in transcriptomics in the near future (Marinov, 2017).

\subsection{Targeted therapy and NGS}

Tumor progression can be followed by relapse (Puig et al., 2008), due to a variety of genomic alterations, which render the cells chemoresistant, resulting in relapse. These studies suggest that a multistep pathway including DNA endoreduplication, polyploidy, followed by depolyploidization and generation of clonogenic escape cells can account for tumor relapse after initial efficacious chemotherapy. Therefore, the adaptation of new investigation strategies (Kumar et al., 2018; Siddiqui et al., 2018) such as testing patients' plasma for epidermal growth factor receptor (EGFR) mutations is ongoing. Though, decision making in treatment strategies is supported nowadays by analysis of tumor DNA extracted from the plasma of cancer patients. However, a multitude of malignant pathologies still lacks biomarkers and those currently used reveal minimal benefits in classifying patients prior to chemotherapeutic treatment (Conteduca et al., 2017).

With emerging personalized targeted treatment strategies that take into consideration differences in tumor biology of different patients $\mathrm{Hu}$ et al., 2015), novel clinical approaches such as plasmid DNA vaccination, improved tyrosine kinase inhibitors (TKIs)-based therapeutics (Leonetti et al., 2019; Sundaresan et al., 2016), as well as application of new chemosensitizers (Worm and Guldberg, 2002; Wu et al., 2014), the contribution of NGS became more valuable in both identification of cancer biomarkers and in selecting the most suitable anticancer treatment modality.

Although comparative analysis showed that droplet digital PCR (ddPCR) is more sensitive and also inexpensive, the advantage of NGS is in its capacity to monitor multiple gene mutations at the same time (Yang et al., 2016). Besides, some mutations can be determined using NGS from liquid biopsies (Mikhaylenko et al., 2018). Thus, NGS significantly contributes to the selection and enhancement of current anticancer treatment regimens.

\section{Atomic Force Microscopy (AFM) in cancer MDR research}

\subsection{Atomic Force Microscopy in biomedical research}

A novel tool appeared recently among the instruments used in cancer research: the atomic force microscope (AFM). This device was invented in 1986 by the Nobel laureate Gerd Binnig to image, at high resolution, electrically insulating surfaces (Binnig et al., 1986). Since the instrument can operate in liquids, it quickly became popular among biologists. Soon after, it appeared that not only does it permit to acquire high-resolution images of biological samples in nearly physiological conditions, but it can also explore their mechanical properties (Kasas and Dietler, 2008), detect the presence of specific molecules on its surface or monitor the sample's metabolic rate. The device records all these data simultaneously and relatively simply, which qualifies AFM as promising research and diagnostic tool.

The AFM essentially consists of a sharp tip that scans the surface of the sample. The tip is fixed at the end of a soft cantilever that deflects accordingly to the topography of the scanned surface. The angular deflection of a laser beam that illuminates the cantilever end, permits to determine the vertical deflection of the lever very precisely, with a resolution that reaches $0.1 \AA$. Depending on the instrument's manufacturer, the tip or the sample is attached to a piezo-electric scanner and is moved along the 3 axes under the control of electric signals sent by a computer. A computer generates a 3D image of the sample's surface by displaying the cantilever deflection at each spot of the scanned sample. Fig. 2 displays the different imaging/data gathering working modes of the AFM that are of potential interest to cancer research and biomedical research.

The main motivation for AFM development was the high-resolution imaging of non-conductive samples. The very first imaging mode implemented on these instruments is the so-called contact mode since the tip is constantly in contact with the sample (Fig. 2A). However, it appeared very quickly that this mode is not appropriate to image weakly attached samples, such as individual proteins or DNA molecules. The lateral forces applied by the tip displace the sample and make it invisible to the AFM. To overcome this drawback, Zhong et al., developed the so-called tapping mode (Fig. 2B) (Zhong et al., 1993). In this mode, the tip oscillates in the vertical axis and touches periodically the sample. In this imaging mode, the tip only applies a vertical force onto the sample, preventing its lateral displacement; it is therefore well adapted to image loosely attached molecules. The third imaging mode is the so-called non-contact mode (Zhong et al., 1993) in which the tip 
is set to oscillate above the sample without touching it (Fig. 2C). The change in the cantilever oscillation frequency that occurs when the tip approaches the sample, serves to calculate the tip-sample distance. Therefore, this imaging mode virtually does not interact with the sample. However, its implementation is complex and is for the moment, restricted to a few laboratories in the world.

The AFM measures mechanical properties by indenting its tip into the sample and monitoring the cantilever deflection during the process (Fig. 2D). The obtained curve, referred to as the indentation curve, displays the force that is needed to indent the tip to a given depth on the sample. Fitting the indentation curve with the appropriate model permits us to calculate the stiffness of the sample, assuming the shape of the AFM tip and some other parameters are well defined. A comprehensive and exhaustive study of this type of measurement can be found in Cappella and Dietler (Cappella and Dietler, 1999).

The detection of the presence of specific molecules expressed on the surface of the sample is achieved by attaching on the AFM tip a molecule that binds to the target (Fig. 2E). By bringing the tip in contact with the sample, the two molecular species attach. During the retraction of the tip, the newly formed link deflects the cantilever downwards unless the cantilever restoring force overcomes the binding force between the two molecules. At this moment, the newly formed bond breaks and the cantilever returns to its rest position. The deflection of the cantilever before the bond breaks, multiplied by the lever spring constant, gives the interaction force between the two molecular species.

A variant of the classical tapping mode is the so-called Peak forcetapping mode. In this mode, the tip is set to oscillate at a low frequency and low amplitude to minimize the force applied onto the sample to tens of piconewtons. One single Peak force image contains information at a nanometric scale about the topography of the adhesion and the mechanical properties (elastic modulus, deformation, and dissipation) of the sample.

The last operating mode of the AFM consists of depositing the sample directly onto the cantilever (Fig. 2F). If the sample is alive, it induces nanometric scale oscillations of the lever that immediately stop as soon the organism dies. The technique is very new and permits to assess rapidly the sensitivity of bacteria to antibiotics. However, several pilot studies suggest its usefulness in the field of cancer research and especially in the detection of anticancer drug resistance.

\subsection{Imaging of cancer cells}

AFM imaging mode can be very useful in several fields of cancer research. The instrument can portray single molecules or molecular complexes in near-physiological conditions. Importantly, it also monitors the structural changes induced by different drugs in real-time. As an illustration, Alonso et al., monitored the topological modifications of DNA upon exposure to doxorubicin (Alonso-Sarduy et al., 2011). At somewhat lower magnification, ex vivo studies performed on lipid bilayers demonstrated the mechanism of action of anticancer drugs on cancer cell membrane rafts (Corsetto et al., 2012). This capability of the AFM is also applicable at a larger scale to single cells. It permits us to study the 3D topography of cellular membranes and partially the organization of uppermost components of the cytoskeleton. Numerous similar studies explored drug effects on the cellular membrane of the whole carcinoma, colorectal, lymphoma and breast cancer cells (Huang et al., 2012; Li et al., 2016a; Venkatesan et al., 2010; Wang et al., 2009a). Quantifying morphological changes affecting 3D surfaces such as cellular membranes as seen by AFM can be very challenging. Simple roughness measurements are not sensitive enough to highlight subtle changes. Analyzing the fractal dimension of the cellular surface could be a valuable alternative to distinguish subtle differences occurring after drug treatment (Starodubtseva et al., 2017a, 2017b; Starodubtseva et al., 2019). All these data strongly suggest that following online cell surface changes upon drug action can help in distinguishing sensitive from resistant cancer cells.

\subsection{Studying mechanical properties of cancer cells}

Numerous links were made in the last decade between alterations of the mechanical properties of cells and pathological states. Among the studied diseases, cancer is certainly the one that focused most on the attention of AFM users. The majority of studies demonstrated that cancer cells are softer than normal cells whereas some, such as hepatocellular cancer cells, cervical carcinoma cells, myeloid and lymphoid leukemia cells were reported stiffer than their normal counterparts (Ding et al., 2015; Lekka, 2016; Rosenbluth et al., 2006; Zhang et al., 2002). The reasons for these modifications are still unknown and subjected to debate (Rianna et al., 2018). During invasion and metastasis formation, cancer cells need to rearrange their cytoskeleton to exert enough force to break down intercellular contacts, start to move and follow their path through the extracellular matrix. These rearrangements inevitably modify the mechanical properties of the cells, since the actin cytoskeleton was demonstrated to play a major role in the determination of the cellular mechanical properties (Kasas et al., 2005). Modifications occurring in cancer not only affect cells but extend also to the extracellular matrix, which changes its stiffness and adhesive properties. The extracellular matrix not only sustains and connects cells but also influences numerous cellular functions (Ulrich et al., 2009). It is also documented to modulate cellular mechanical properties (Solon et al., 2007). By considering the mechanical properties alterations that are occurring in both, cells and extracellular matrix, it becomes possible to distinguish by AFM cancerous tissue from the normal one (Plodinec et al., 2012). The sensitivity of cancer cells to drugs can also be explored by monitoring cellular mechanical properties. Sharma et al. noticed a significant difference in the mechanical properties of cisplatin sensitive and resistant ovarian cancer cells (Sharma et al., 2012). The authors attributed the difference to changes in the actin cytoskeleton. Further studies led by Seo et al., confirmed that the acquisition of cisplatin resistance by ovarian cancer cells induces a reorganization of the actin cytoskeleton (Seo et al., 2015). Similar studies were carried on the prostate, and B-lymphoma cancer cells under various chemotherapeutic conditions and demonstrated that chemotherapeutic treatments induce an increase in the stiffness of the cells (Li et al., 2015b; Ren et al., 2015). These studies suggest that mechanical properties can be used to discriminate in a close future sensitive from resistant cell types. AFM could be included in the diagnostic instrumentation chain. A comprehensive recent review of nanomechanical fingerprinting of cancer can be found in Stylianou et al., (Stylianou et al., 2018).

\subsection{Studying adhesive properties of cancer cells}

Xiao et al., demonstrated in 2013 that not only the mechanical properties of cancer cells are useful to monitor cellular response to chemotherapy but also their adhesive properties (Xiao et al., 2013). The team compared non-small cell lung cancer cell lines (A549) with noncancerous human primary small airway epithelial cells. The AFM measurements revealed an increased stiffness and increased adherence of the non-cancerous population. Brief exposure to doxorubicin for $4 \mathrm{~h}$ in lung cancer cell lines highlighted an increase of adherence and stiffness of the cancer cells and an opposite modification of both parameters in the non-cancerous cells. This study indicates the potential of using cell adhesion modifications to assess drug activity in cancer cell lines.

More specific adhesive properties can also be explored by AFM by tracking single miRNA molecules. miRNA deregulation is observed in cancer and several cardiovascular and neurological diseases (Gebert and MacRae, 2019; Lujambio and Lowe, 2012). It was demonstrated that the levels of certain miRNA can even predict cancer prognosis (Shell et al., 2007). Thus, miRNA quantification emerged quickly as an important topic in the field of cancer research. AFM contributes to the development of this research field by detecting the miRNA in single cells without reverse transcription or amplification. The measurement 
consists of fixing cells, removing their plasma membrane and scanning the remaining cell components with a DNA probe attached to the tip and that is complementary to the specific miRNA (Koo et al., 2016). This type of investigation can be very useful to assess drug activity at the single-cell level and it can be speculated that miRNA monitoring can be a useful marker in the detection of drug resistance.

\subsection{Characterization of extracellular vesicles by AFM}

In recent years, the capacities of the AFM were applied to explore the abundance, the morphology as well the mechanical properties of exosomes and other extracellular vesicles. These organelles have a diameter in a range between 30 and $120 \mathrm{~nm}$ and mediate a multitude of intercellular communications (Yamamoto et al., 2019). They exhibit several surface-bound proteins and receptors. The cargo of extracellular vesicles consists of proteins and genetic material such as miRNA, mRNA proteins and DNA molecules. They are present in several body fluids such as blood, cerebrospinal fluid, saliva, urine, and amniotic liquid (Rahbarghazi et al., 2019). These organelles play an important role in numerous infectious diseases, neurodegenerative processes, and cancer (Jan et al., 2019). Compared to the traditional investigation tools such as optical and electron microscopy, AFM presents an interesting exploration tool to characterize these organelles. It can operate in a nearly physiological environment and investigate the extracellular vesicle abundance, morphology, mechanical properties, and biomolecular content. Extracellular vesicles monitoring during chemotherapy could be an additional marker for treatment efficiency. A comprehensive review of the potential use of AFM in the field of extracellular vesicles was recently published by Sharma et al., (Sharma et al., 2018).

\subsection{Using nanomotion to discriminate cancer MDR cells}

It was also demonstrated that AFM-based detection of nanomotion can monitor the life-death transitions of single cells upon exposure to cytotoxic drugs (Longo et al., 2013). The technique is essentially employed for bacteria antibiotic sensitivity tests. The test lasts a dozen of minutes and is label-free. The method can be extended to cancer research to determine the sensitivity or resistance of cancer cells to anticancer drugs. The first experiments made with cancer cells (Kasas et al., 2015) were rapidly and successfully reproduced by other independent research teams. Wu et al. monitored the action of paclitaxel on the oscillation pattern of breast cancer cell lines (MCF-7) (Wu et al., 2016). Expectedly, the amplitude of oscillations dramatically dropped after the injection of the drug in the analysis chamber. The technique is relatively simple, can apply one to dozens of cells simultaneously and importantly, is completely label-free. In terms of sensitivity, in these preliminary experiments, the authors solely monitored life-death transitions. However, the technique is sensitive enough to follow subtler metabolic rate changes such as those occurring during cytoskeletal rearrangements. It, therefore, can potentially highlight subtler drug-induced effects on the cytoskeleton hence paving the way towards novel avenues for cancer research.

\section{Single live-cell tracking for identification of drug-resistant and aggressive cancer cells}

Single live-cell imaging has become widely used to study cancer particularly when it can address intra-tumor and inter-tumor heterogeneity and complexity. Various cell tracking methodologies and software tools progress towards quantitative analysis of the spatio-temporal dynamics of heterogeneous cell populations present in tumors. However, direct monitoring (tracking) of many initial single cells and their descendants during several days in realistic 3D tumor environments has so far not been technically feasible. Developments in lensfree microscopy may change this situation (Berdeu et al., 2018). Labelfree single-cell tracking in 3D space is not currently feasible combined with subsequent biochemical analyses of individually tracked cells while keeping their track identity. 2D single-cell tracking can more easily supplement subsequent biochemical analyses and act as surrogate measurements for the 3D situation. Holo-tomographic microscopy (HTM) may here provide high-resolution ground-truth and facilitate tracking of cellular organelles during shorter periods inside an otherwise sparse sampling regime. HTM is label-free, non-phototoxic microscopy analyzing the fine changes of a cell's refractive indices (RIs) in 3D. Hence, by combining HTM with epifluorescence, one can show that cellular organelles including lipid droplets and mitochondria show a specific RI signature that distinguishes them with high resolution and contrast. Hence, HTM may allow following the dynamics of mitochondria, lipid droplets as well as that of endocytic structures in live cells and beyond (Sandoz et al., 2018). However, the tracking of intracellular organelles normally requires both high resolution and image sampling rates that in principle could create phototoxicity and heat. One may assume that long term rapid high-resolution sampling for thousands of cells would produce an unmanageable amount of data. This in principle may not be true if the analysis takes place in real-time ("on the fly") and only accumulated data from analyses are stored. This approach has conceptual similarity to so-called compressive sampling where sensor data are compressed while measurements take place.

The advance of applications of single-cell tracking is likely to actualize a need for the design of new cell lines to improve the selection of experimental cells that are fit for tracking and analysis. For example, some types of cells tend to clump together complicating and restricting practical long term tracking. Stably transfected cell lines can help solve this problem. These cells are transfected with fluorescently tagged proteins that are commercially available. The use of chromobody technology is another alternative to visualize the localization and dynamics of cellular targets for drug screening and trace cellular processes (Traenkle and Rothbauer, 2017).

Tracking of single live cells growing as monolayers currently gave more precise insight into cellular dynamics and cell fate decisions as compared to still images taken from fixed cells (Cooper and Bakal, 2017). It provides more possibilities to explore critical biological events in cell populations, such as proliferation, migration, differentiation, cell death or to reveal rare or emergent cell sub-populations (Gascoigne and Taylor, 2008; Gómez-Villafuertes et al., 2017; Korsnes and Korsnes, 2018; Moussy et al., 2017; Piltti et al., 2018; Shaffer et al., 2017). 2D single-cell tracking is still considered technically challenging due to many experimental settings to be considered such as cultivation conditions of distinct cell populations, appropriate cell culture density, changes in individual cell morphology, light conditions, imaging frequency, adjustment of focusing and lack of software tools (Al-Kofahi et al., 2006; Coutu and Schroeder, 2013; Meijering et al., 2012; Schroeder, 2011). The majority of approaches for cell tracking has been based on cell segmentation or frame-to-frame linking of segmented organelles (Coutu and Schroeder, 2013; Meijering et al., 2012; Schroeder, 2011). Fluorescence-based long term tracking, although commonly used, may produce phototoxicity or unwanted artifacts (Gómez-Villafuertes et al., 2017; Milan et al., 2016). Further advancement of lens-free microscopy may open new avenues for automatic 2Dbased single-cell tracking (Rempfler et al., 2018).

Single-cell tracking can complement other single-cell analyses such as DNA/RNA sequencing. However, to achieve maximum combined benefit from both technologies, it is imperative that those cells previously monitored by time-lapse are later re-identified and individually collected for the secondary analysis (Gómez-Villafuertes et al., 2017). This can be achieved by using microscopes including positional coordinates, by applying fluorescent reporters for specific cells or by using chambers with labeled grids that can identify individual cells as references (Gómez-Villafuertes et al., 2017). Automatic recognition based on relative positions between cells is also a possible approach to re-identify cells.

Single-cell tracking combined with other end-point analyses such as 
indirect immunofluorescence has been useful to identify proteins of interest or cell division markers. Cell tracking has so far been mainly based on semi-automatic visual guidance/control or tailored recording equipment (Sato et al., 2018, 2016). There are currently only a few published results based on systematic single-cell tracking for several days showing a complete lineage tracing using standard equipment for video recording (Korsnes and Korsnes, 2018, 2017, 2015). Several studies claim the production of automatic single-cell tracking based on computer vision algorithms (Akram et al., 2017; Huth et al., 2010; Tinevez et al., 2017). However, their contributions lack illustrations evidencing a complete lineage tracing from their recordings (Al-Kofahi et al., 2006; Davis et al., 2007; Errington et al., 2005; Khan et al., 2007; Sato et al., 2018, 2016). The presently available tools for single-cell tracking are missing methodology to resolve ambiguities such as joint multi-target tracking and classification (Hilsenbeck et al., 2016; Hormoz et al., 2016; Rapoport et al., 2011; Stadler et al., 2018). However, the development of software tracking tools is under constant improvement (Davis et al., 2007; Errington et al., 2005; Khan et al., 2007; Koh et al., 2017; May et al., 2018). The latest advancements appear to focus on automation based on localized image analysis and recognition. Statistics from cell lineages (pedigree trees), feature extraction and identification of inheritance of traits, can contribute to discover and to resolve tracking ambiguities and thereby contribute to a holistic approach for cell tracking.

\subsection{Proxy measurements from $2 D$ light microscopy recordings}

The purpose of single-cell tracking from 2D light microscopy recordings is not to mimic how they may behave at various complex environments but rather reveal the inherent properties of cells. Experiments with 3D-models can presumably help to utilize results from 2D-models for the improved prognosis of cancer. Conceptually simple single-cell tracking from 2D light microscopy recordings can provide proxy observations of inheritance of traits via measurements of cells related via pedigree trees. It can also provide information related to the process of cell division as well for example the tendency of cellular senescence for subgroups of cells due to treatments. New information is in general available when measurements from cells can be related to lineages.

The following list indicates actual types of observables from 2D light microscopy recordings and their possible biological relevance:

- Parameters from movements. A Levy flight model may fit single-cell tracking data (Huda et al., 2018). It can reflect a change in the persistence of directions of movements caused by a change in the cytoskeleton and cell shape. Stress often tends to affect the movements and motility of cells.

- Changes in cell shape can correlate with its signaling history and state (Cooper and Bakal, 2017).

- Vacuolization and vacuole inheritance may play an important role in cell death and survival.

- Nuclear changes based on tracking and extracting features from fluorescent-labeled nuclei (Bolgioni et al., 2018; Cooper et al., 2017).

- Variation in the size of pedigree trees for a population can indicate heterogeneity and potential for long term change in the composition of cells (Korsnes and Korsnes, 2018). The non-symmetric shape of pedigree trees increases the likelihood of mitotic failures.

- Correlation of cell death modalities between sister cells indicates signaling downstream pedigree trees (Korsnes and Korsnes, 2018).

- The time from observed onset of mitosis until actual cell division.

- The time between subsequent events of mitosis.

- Mitotic cell fate (Bolgioni et al., 2018).

- Changes in the texture of cell images can indicate cytoskeleton disruption or membrane rupture.

- Parameters from cell rounding (duration, size, and shape). Improper cell rounding may indicate mitotic failure (Lancaster et al., 2013).

- Contact between cells can affect them and their descendants.

- Correlations between physical contact and movements (a tendency for cells to stick together). Cells may need time to transfer information between them.

- Correlations between movements and physical contact between cells may increase the likelihood of intercellular influence.

- Synchronization of cell division among adjacent cells. Synchronous cell division may indicate intercellular communication.

- Cell rounding and its duration during mitosis. If there is no proper cell rounding or its duration is outside the normal range, then chromosomal instability may take place (Lancaster et al., 2013).

In general, the above observables will depend on treatments and cultivation conditions. Big data analyses can support the extraction of usable knowledge from such exhaustive and presumably weakly related data. In addition, it can be used to perform data mining utilizing extensive databases containing results from many similar experiments with various toxic exposure and cell types.

Korsnes and Korsnes demonstrated correlations between parameters derived from the movements of sister cells using the computer program KoBio Celltrack (https://korsnesbiocomputing.no) (Korsnes and Korsnes, 2018). They also showed correlations between cell death modalities for sister cells following changes in cell morphology. The program visualizes search for correlations resulting in hypothesis formulation. Fig. 3 is an example of such visualization; it shows A549 nonsmall cell lung cancer cells exposed to the marine toxin yessotoxin (YTX) at a concentration of $500 \mathrm{nM}$. The tracks of two pairs of sister cells followed during $0-10 \mathrm{~h}$ after the division of their mothers are superimposed on Fig. 3A. Fig. 3 also includes corresponding pedigree trees for these sister cells (Fig. 3B, C). The cells belonging to the small pedigree tend finally to die (Fig. 3C) and move significantly faster than the thriving cells belonging to the large pedigree tree (Fig. 3B). This recording led to the idea that observation of movements may serve as a proxy for cellular stress and inheritance (and potentially cell death in mitosis or mitotic catastrophe for some cells).

Such observations of correlations can be used for many purposes. Drug treatment of cells can affect inheritance. This implies that changes in inheritance can be considered as a response to drug treatment. Measurements of inheritance of traits may also be used for technical quality control of tracking as well as control of cell cultivation. Inheritance of signatures related to movements also has an interest in the identification of sub-populations and their level of cellular stress.

\section{Microfluidic technology to study the MDR phenotype in cancer}

The microfluidic technology for cell culture applications, also known as organ-on-chip, designs and fabricates microfluidic devices made of silicones, glass or thermoplastic materials (polystyrene, cyclic olefin copolymer or similar) that are structured with cameras and channels to fit the cell scale. This scale allows the recreation of complex multicellular architectures (3D cultures surrounded by epithelial barriers and/or vascular networks, etc.) and the mechanical and chemical physiological environment in a well-controlled manner. Important hallmarks of cancer and/or its TME including hypoxia, cell invasion/ metastasis, and angiogenesis which can be simulated in vitro using microfluidic chips are highlighted in Fig. 4. These micro-physiological systems have been used to mimic some of the most relevant characteristics of tumor progression and metastasis, while cellular changes and adaptations to different environmental conditions can be easily monitored in real-time under the microscope (Hachey and Hughes, 2018; Shang et al., 2019; Sontheimer-Phelps et al., 2019).

\subsection{Studying proliferative characteristics of cancer cells}

One of the fundamental characteristics of tumor progression and 


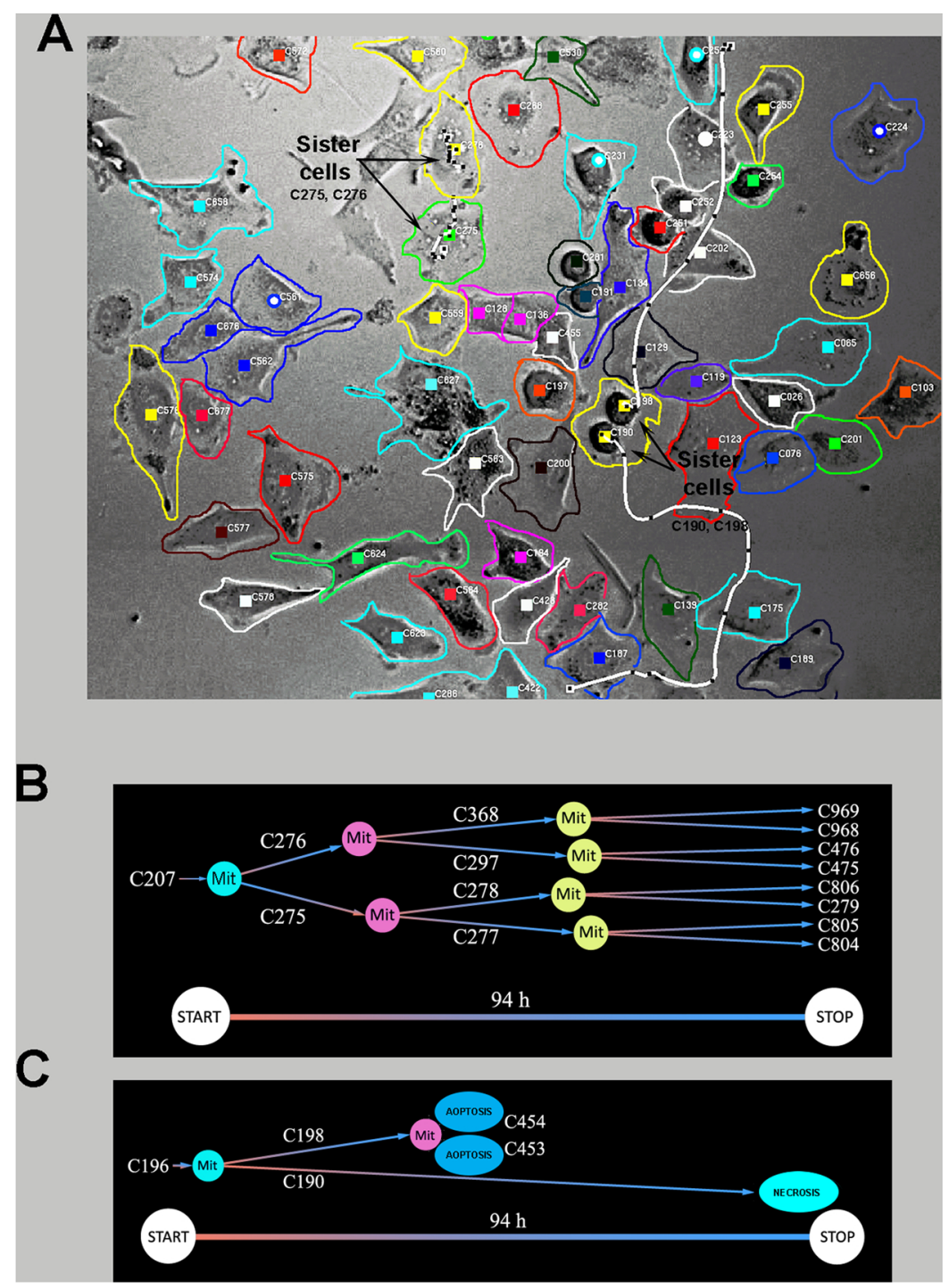

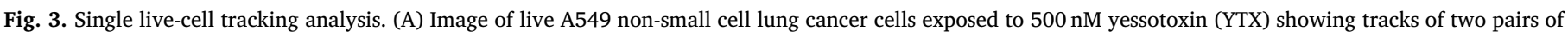

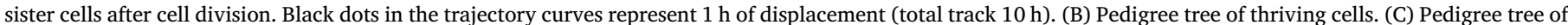
stressed cells.

metastasis is sustained proliferation mediated by deregulated signaling pathways accompanied by a lack of response to growth suppressor signals. The utility of microfluidic devices to study these processes has been described recently (Hassell et al., 2017). A decrease in EGFR and phosphorylated EGFR levels was observed in lung cancer cells subjected to mechanical stress which was used to simulate the respiration process inside a microfluidic device. To achieve this, the authors designed a microfluidic device with two chambers separated by a porous and deformable membrane inducing the mechanical stimuli over the cells in a physiological manner. Another example has been described by Lang et al., who constructed a device that confronted different cell types (breast cancer cells and stromal fibroblasts) to facilitate intercellular communication (Lang et al., 2013). However, they revealed that the modified expression of estrogen receptors in breast cancer cells was not related to the heterotypic cell-cell contact. The proliferation rates of MCF-7 cells were responsible for the observed changes in the estrogen receptor expression. Another example of how microfluidic devices could simulate complex physiological proliferation processes was recently described (Ayuso et al., 2017). Proliferation was observed only in glioblastoma cells that had migrated in response to an oxygen gradient. In this case, microfluidic devices were manufactured to be impermeable to gases, forcing all the nutrients and oxygen to reach the central chamber with cells embedded in 3D hydrogel through the perfused lateral channels. When only one lateral channel was perfused, the cells far from the perfused channels migrated towards higher oxygen concentrations. No cell proliferation was observed when both lateral channels were perfused or during the migration process. Glioblastoma cells proliferated exclusively once they reached the oxygen-rich area.

\subsection{Studying changes in cellular metabolism}

The TME is characterized by heterogeneous zones with different physicochemical characteristics like chemical (cytokines, nutrients or oxygen) or physical gradients (stiffness). The generation of these gradients can be achieved in multiple ways in a microfluidic device (Somaweera et al., 2016). To study the effect of nutrient and oxygen gradients, Ayuso et al., cultured glioblastoma and colorectal cancer cells in a microfluidic device that is not permeable to gases in which, due to the high cell density, zones of self-induced ischemia were created by cellular metabolism (Ayuso et al., 2016). In these metabolically heterogeneous models, cancer cell sensitivity to different chemotherapeutic drugs was assessed demonstrating variations in their effect due to the metabolic location of cancer cells. Moreover, the deregulation of the cellular energetic mechanisms present in the TME can induce the 


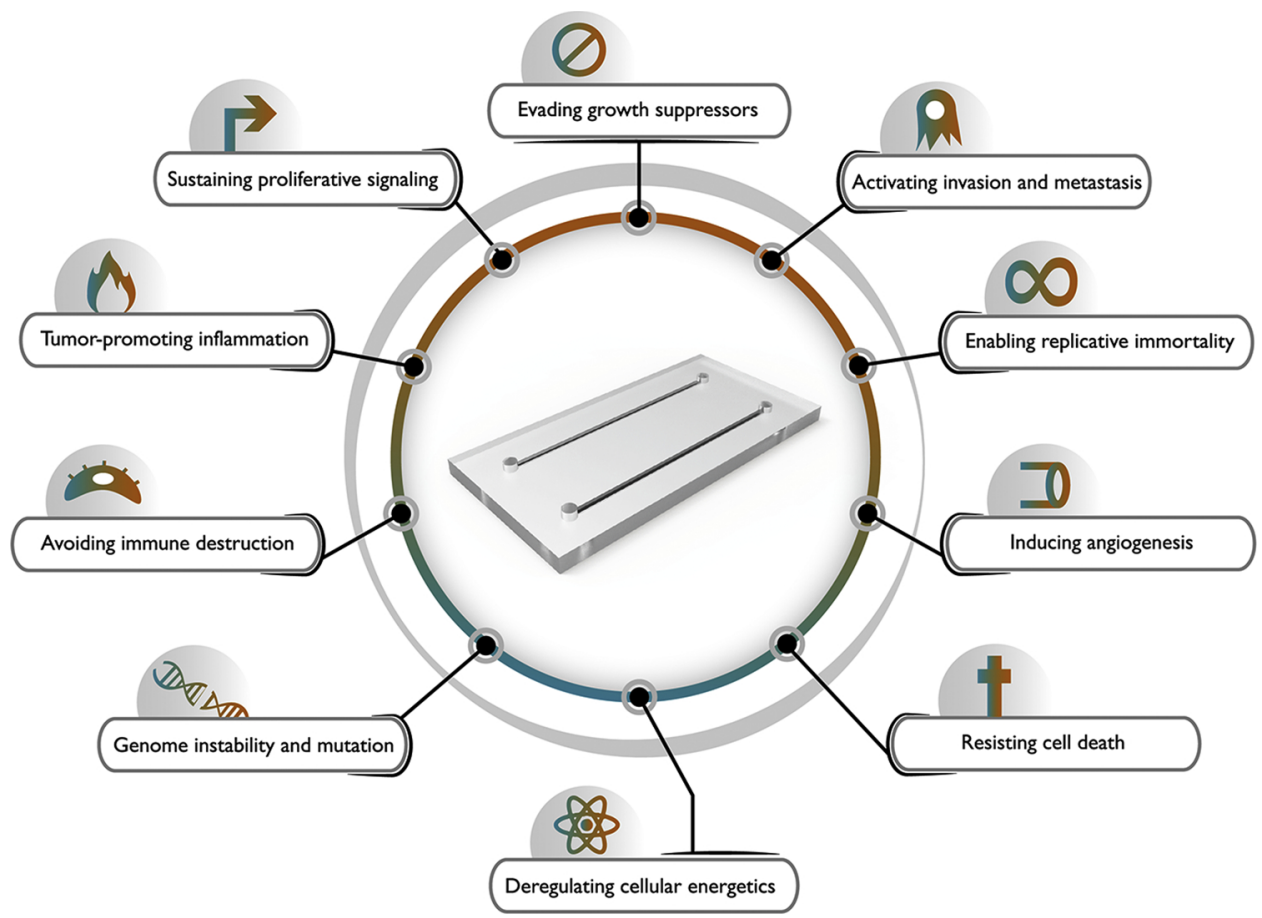

Fig. 4. Hallmarks of microfluidic chips application in cancer research.

production of reactive oxygen species (ROS). The oxidative state, modulated by the antioxidant coenzyme Q10, and its relation with the cell death and resistance mechanisms have been studied by Burić et al., in a glioblastoma model (Burić et al., 2019). A significant increase in temozolomide sensitivity upon combined treatment with coenzyme Q10 was observed in drug-resistant glioblastoma cells located in the highly oxygenated zone of the microfluidic chip when compared to the hypoxic area.

\subsection{Studying tumor metastatic behavior}

Several reviews and research articles have recently reported different approaches that simulate the process of tumor metastasis using microfluidics (Caballero et al., 2017; Lee et al., 2016; Portillo-Lara and Annabi, 2016; Sleeboom et al., 2018; Sontheimer-Phelps et al., 2019). Hao et al., described invasion profiles of different breast cancer cell phenotypes in newly formed bone tissue inside a microfluidic device (Hao et al., 2018). Fluorescent MDA-MB-231-BRMS1 ${ }^{\text {GFP }}$ cells showed no significant interactions with the osteoblastic tissues formed on-chip. However, in co-culture with osteoblastic tissue, MDA-MB-231 ${ }^{\text {GFP }}$ cells increased their invasive capacity. This study opened the door to the phenotypic characterization of circulating breast cancer cells to predict the probability of bone metastasis occurring in breast cancer patients. On the other hand, several research groups have also developed multiorgan microfluidic chips to study tropism toward other organs which is characteristic of some cancers. Along this line, Alemán et al., corroborated in vitro the preference of colorectal cancer organoids to metastasize to liver and lung tissues (Aleman and Skardal, 2019), while Xu et al., undertook similar studies by demonstrating the tropism of lung cancer cells to nervous, bone, and liver tissues (Xu et al., 2016). Another approach in studying metastasis - vascular interaction with the tumor cells was explored (Boussommier-Calleja et al., 2019; Chen et al., 2017). Thus, Boussommier-Calleja et al., described the role of monocytes in the extravasation of tumor cells in 3D vasculature models inside microfluidic devices (Boussommier-Calleja et al., 2019). Reduction in trans-endothelial migration mediated by soluble factors released by monocytes was observed. However, macrophages derived from circulating monocytes showed no significant effect on extravasation processes. Moreover, the formation of new blood vessels has been also simulated in microfluidic devices (Haase and Kamm, 2017). Several microfluidic designs have been employed to mimic the angiogenic process. Lee et al. described that the presence of U87 glioblastoma cells was able to markedly increase the sprout numbers and coverage areas of the microvessels compared to cancer cell-free controls (Lee et al., 2014). Agarwal et al., embedded cancer cells in alginate capsules to recapitulate the 3D structures (Agarwal et al., 2017). In a posterior step, those capsules were assembled with other cells from the TME (endothelial and stromal cells) to resemble a macroscale 3D vascularized tumor. Their results showed a very significant increase (between 4.7- to 140 -fold) in drug resistance to doxorubicin when compared to the $2 \mathrm{D}$ culturing method. Other research groups have focused their research to test the impact of antiangiogenic drugs using microfluidic devices, providing new applications of this technology to combat cancer, particularly against chemoresistant tumors (Kim et al., 2015).

\subsection{Studying interactions with the immune system}

Immune system cells are also present in the TME where their role has been modulated or compromised by the tumor cells (Pardoll, 2012). Therefore, modulation of the immune response is considered a promising therapeutic strategy and recently immune-tumor interaction was evaluated in microfluidic chips (Aref et al., 2018; Moore et al., 2018). Namely, small specimens of patient biopsies were placed in the interior of microfluidic chips to assess the efficacy of immune checkpoint inhibitors. In addition, recently approved personalized therapy with genetically modified CAR-T cells was also tested in a biomimetic environment on-chip by using co-culturing of liver cancer cells with CAR$\mathrm{T}$ cells (Pavesi et al., 2017). Co-culture was performed within a microfluidic device capable of controlling the environmental conditions such as the oxygen levels and the presence of inflammatory cytokines.

It is well established that inflammation affects several hallmarks of cancer and its role in carcinogenesis and cancer progression has been well established (Coussens and Werb, 2002; Kon and Benhar, 2019; Taniguchi and Karin, 2018; Todoric and Karin, 2019). Being a complex process mediated by several cell types of the TME, inflammation is not possible to study in-depth with classical culturing methods. Therefore, 
several approaches using different microfluidic devices to mimic the immune-cancer interactions were developed (Boussommier-Calleja et al., 2016). A promising design to study damage-associated molecular patterns after post-ischemic inflammation has been reported (Ayuso et al., 2016).

\section{Microfluidic-based 3D cell cultures for drug screening}

The development of microfluidic technology and its application in designing microfluidic-based 3D cell cultures have made breakthroughs in overcoming drawbacks in evaluating anti-cancer drug sensitivity/ resistance in vitro.

\subsection{Drug resistance in microfluidic-based $3 D$ cultures}

3D cultures are generally more resistant to chemotherapeutics than monolayer cultures (Jo et al., 2018); this particularly refers to microfluidic-based cultures. In recent years, several research groups have reported this phenomenon. Ozcelikkale et al. (2017) used their TME-onchip (T-MOC), to mimic drug transport in tumor tissue (Ozcelikkale et al., 2017). They observed that two breast carcinoma cell lines with different molecular profiles (MCF-7 and MDA-MB-231) were both more chemoresistant to doxorubicin (free or nanoparticle-loaded) in T-MOC than in 2D cultures. Moreover, triple-negative breast cancer cells, MDAMB-231, displayed increased resistance compared to MCF-7 in the TMOC platform. The authors revealed that the absence of eIF3a was one of the major mechanisms of drug resistance in both cell lines grown in the microfluidic chip, while overexpression of the hyaluronic acid receptor CD44 in the MDA-MB-231 cell line appeared responsible for its increased chemoresistance in T-MOC. In another microfluidic device, a butterfly-shaped microchip developed by Yildiz-Ozturk and colleagues, MCF-7 and MDA-MB-231 cells were also more resistant to doxorubicin and the antioxidant carnosic acid, than in a 2D culture system (YildizOzturk et al., 2017).

Uhl et al. showed that human colorectal cancer cells HCT116 were more resistant to conventional chemotherapeutics doxorubicin, paclitaxel, and capecitabine when grown as tumor spheroids within the bilayer microfluidic system (Uhl and Liu, 2019). Another research group compared the responsiveness of the same cells to 5-fluorouracil, oxaliplatin, vincristine, and sorafenib in their "tumor-on-a-chip" platform and $2 \mathrm{D}$ culture, showing increased resistance to all tested drugs in a microfluidic device (Sobrino et al., 2016).

Another study reported that both sensitive and MDR breast carcinoma cell lines, MCF-7S and MCF-7R, were more resistant to doxorubicin in the microfluidic system compared to $2 \mathrm{D}$ monolayer (Sabhachandani et al., 2019). Interestingly, in 3D perfusion systems, sensitive and drug-resistant cell lines had almost the same response to doxorubicin at lower drug concentrations $(1 \mu \mathrm{M}$ and $5 \mu \mathrm{M})$, while drugresistant cells become more resistant only at higher doxorubicin concentrations (10 and $20 \mu \mathrm{M}$ ) (Wang et al., 2019b).

3D microfluidic-based cultures are also more resistant to cytotoxic drugs than static 3D cultures (Pradhan et al., 2018; Yildiz-Ozturk et al., 2017). These differences in drug response in 3D models point to the significance of the presence of media and drug flow in cell culture systems for a more clinically relevant evaluation of anticancer drug efficacy.

It is interesting to note, unlike other authors, that Jo et al., observed that glioblastoma T98 $\mathrm{G}$ cells displayed a better response to doxorubicin in microfluidic chip compared to other static 3D cultures and even 2D cultures (Jo et al., 2018). Detailed analyses revealed that in perfusion culture, cells were almost completely removed by media flow due to their loss of cell adhesion and attachment ability upon doxorubicin treatment.

Importantly, it was shown that data obtained from microfluidic devices on drug responsiveness of both breast carcinoma and bladder cancer cell lines established from patients are similar to those collected from the corresponding in vivo experiments, thus confirming the validity of the use of microfluidic-based cultures in anticancer drug screening (Gheibi et al., 2017; Ozcelikkale et al., 2017).

Microfluidic technology can be also useful to separate cells based on their intrinsic characteristics, including cell size. Therefore, several microfluidic devices were developed to investigate the effect of different cell/spheroid size on drug susceptibility (Pang et al., 2016; Patra et al., 2016; Zuchowska et al., 2017). Two groups reported that both single cells and spheroids of smaller size are more resistant to the tested drugs, vincristine, and 5-fluorouracil, respectively (Pang et al., 2016; Zuchowska et al., 2017). However, according to the study of Patra et al., the effect of spheroid size on drug response depends on the type of applied drug; smaller HepG2 tumor spheroids are more sensitive to cisplatin, while the cytotoxic effect is opposite for resveratrol and tirapazamine treatments (Patra et al., 2016).

\subsection{Microenvironment effects on drug sensitivity in microfluidic-based $3 D$ cultures}

The presence of various physicochemical conditions and distinct cellular components in tumors, significantly affect the response to chemotherapy (Table 2). Microfluidic technology enabled us to introduce these tumor-related factors in cell cultures under controlled settings and to monitor their impact on drug response in a single device.

Hypoxia present in tumor tissue is one of the major TME conditions contributing to chemoresistance. Thus, its presence in $3 \mathrm{D}$ culture is essential to obtain more clinically relevant results on drug cytotoxicity. Microfluidic technology provides a platform for adjusting the oxygen level to perform more accurate in vitro drug screening. Li and colleagues designed a microfluidic chip which generates an oxygen gradient (Li et al., 2018). They confirmed its feasibility for drug screening on SF767 glioma cells and NSCLC A549 cells using two drugs differentially active under hypoxic conditions, tirapazamine and bleomycin. Another research group developed a microfluidic device to study drug resistance development under different oxygen levels (Germain et al., 2016). They showed that hypoxia-induced a rapid acquisition of drug resistance in prostate cancer cells, PC3, to staurosporine within $30 \mathrm{~min}$, but this effect was reversed after switching to normoxic conditions.

The presence of media flow in microfluidic devices enables studying the effects of shear stress (normally present in tumor tissue) on drug toxicity, which is not possible to examine in other in vitro experimental settings. A study on a microfluidic device with two different continuous flow rates revealed that cultured ovarian cancer SKOV-3 cell spheroids developed resistance to cisplatin and paclitaxel. This shear stress-induced chemoresistance was mediated by increased expression of ATPBinding Cassette (ABC) transporters, P-glycoprotein (ABCB1) and Breast cancer resistance protein (ABCG2), that was not observed under static conditions (Ip et al., 2016).

Apart from fluid shear stress, the mechanical effects of physiological movements could also be studied in microfluidic-based 3D cultures. Hassel et al. developed lung cancer-organ-on-a-chip that incorporates different cells, malignant (human H1975 lung adenocarcinoma cells) and non-cancerous (human primary alveolar epithelial cells and human lung microvascular endothelial cells), and which mimics physiological breathing motions (Hassell et al., 2017). The authors showed that breathing motions contributed to the resistance of EGFR mutated cells to a tyrosine kinase inhibitor, a phenomenon commonly noticed in NSCLC (Leonetti et al., 2019). The observed resistance was mediated by increased activation of EGFR and MET protein kinases.

\subsection{Drug screening in microfluidic-based $3 D$ co-cultures}

The application of microfluidic platforms is particularly suitable for establishing 3D co-cultures of two or more cell types (Table 2). Microfluidic technology, with constant fluid perfusion, provides the appropriate spatial organization of different cell lines, therefore 


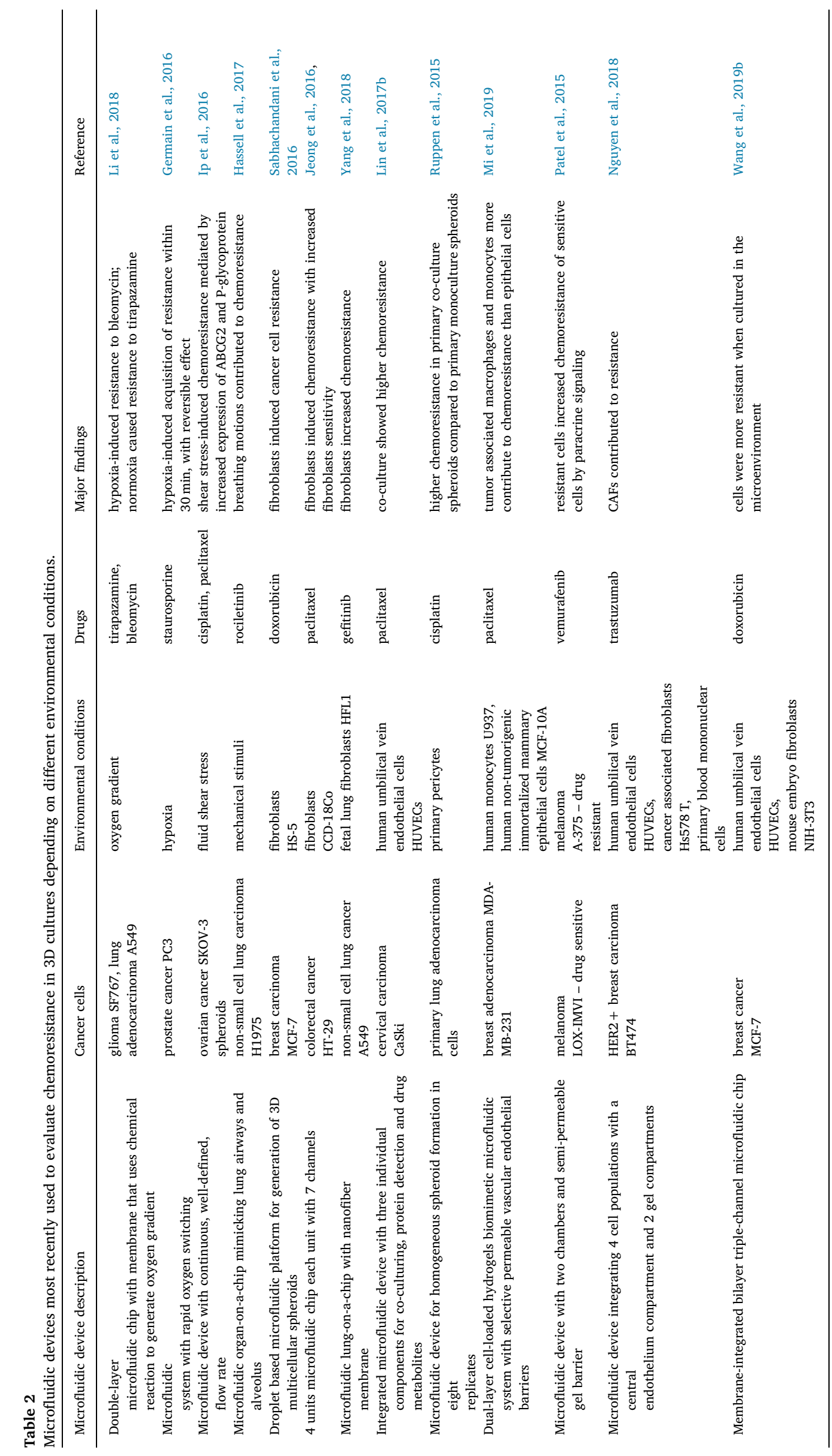


mimicking their normal physiological interactions. This is particularly important for the evaluation of drug cytotoxicity and studying the microenvironmental effects on drug sensitivity in 3D in vitro systems.

Several studies have shown that co-culturing cancer cells with fibroblasts in microfluidic devices induced cancer cell resistance (Jeong et al., 2016; Sabhachandani et al., 2016; Yang et al., 2018), and at the same time increased sensitivity of fibroblasts to tested drugs (Jeong et al., 2016; Sabhachandani et al., 2016). Jeong and colleagues proposed that this effect in colorectal tumor spheroids could be at least in part due to their increased fibronectin expression that coincides with the reduced drug uptake (Jeong et al., 2016).

Excluding fibroblasts, endothelial cells also contribute to the resistance of cancer cells in 3D microfluidic-based co-cultures (Lin et al., 2017b). According to Lin et al., resistance of cervical carcinoma cells to paclitaxel in the presence of human umbilical vein endothelial cells (HUVECs) in microfluidic chip, is associated with higher cell viability, increased expression of angiogenic proteins and active redox system (low ROS and high GSH level) (Lin et al., 2017b).

Pericytes are another tumor-associated cell type that contributes to the chemoresistance of cancer cells in microfluidic co-culture. It was shown that spheroids of primary lung adenocarcinoma epithelial tumor cells co-cultured with primary pericytes are less responsive to cisplatin perfusion than PLETCs monoculture (Ruppen et al., 2015)

Different non-malignant cell types exert different effects on cancerous cells in 3D microfluidic co-cultures. Mi and colleagues showed that tumor-associated macrophages and monocytes contribute more to the survival of breast carcinoma cell lines in response to paclitaxel treatment in the microfluidic device when compared to epithelial cells (Mi et al., 2019).

To study paracrine interactions that confer resistance of BRAF mutated melanoma cells to the BRAF inhibitor, vemurafenib, Patel et al., developed a microfluidic device for co-culture pairs of sensitive and drug-resistant cells (Patel et al., 2015). They demonstrated that in response to vemurafenib, drug-resistant cells exert a protective effect on sensitive cells. This effect was mediated by FGF-2/FGFR signaling and reactivation of the MAPK pathway downstream of BRAF.

Scientists and engineers have gone even a step further and developed several models of tumors/organs-on-a-chip that are comprised of complex co-cultures of malignant cells and multiple non-cancerous tumor-associated cells, such as endothelial cells, epithelial cells, immune cells and fibroblasts (Du et al., 2018; Nguyen et al., 2018; Wang et al., 2019b). These 3D microfluidic systems authentically mimic complex tumor structures and multicellular interactions and therefore are valuable platforms for more reliable preclinical drug testing. For example, Wang and colleagues have shown that MCF-7 breast carcinoma cells are more resistant to doxorubicin in the microfluidic chip when cultured with spatially organized endothelial cells and fibroblasts than without these cells (Wang et al., 2019b).

\subsection{Single and multiple drug evaluation in microfluidic-based $3 D$ cultures}

An important aspect of every drug screening process is defining the most appropriate drug concentration/dose that will exert the expected cellular response. Microfluidic-based 3D cultures have found their application in this part of the drug discovery process as well. Several research groups have developed different microfluidic platforms for culturing cancer cells in a drug concentration gradient (Han et al., 2016; Lim and Park, 2018; Lin et al., 2017a, 2019), therefore making a step forward towards rationally selecting personalized therapeutic drug dose.

These microfluidic systems, that generate spatial drug concentration gradient in long-term cultures, also allow studying the development and mechanisms underlying drug resistance. In two independent studies, the authors showed that prostate epithelial cancer PC3 cells and glioblastoma U87 cells were initially eliminated in the region of high drug concentration in microfluidic chips with the spatial drug concentration gradient. However, cancer cells soon repopulated this area due to the emergence of a drug-resistant cell sub-population and its migration to high drug concentration region (Han et al., 2016; Lin et al., 2017a). Han et al. extracted these resistant U87 cells, which repopulated the Cancer Drug Resistance Accelerator chip upon doxorubicin treatment, and revealed that increased drug efflux activity was the main cause of their doxorubicin resistance (Han et al., 2016). They also performed exome and transcriptome sequencing and identified several mutated genes (CHD1 and FLNA) related to doxorubicin resistance, as well as a significant number of differentially expressed genes associated with immune response, doxorubicin metabolism and NF- $\kappa \mathrm{B}$ signaling. In a recent study by Lin and colleagues (Lin et al., 2019), the authors revealed that PC3 cells moved from low to high docetaxel concentration regions in which these cells were transformed into polyploid giant cancer cells, known as major mediators of therapy resistance in prostate cancer. To distinguish drug-sensitive and drugtolerant/resistant cells, Pandya et al., developed a microfluidic device with an electrical sensing component which measures electrical conductivity changes after cell lysis in response to hydrodynamic drug flow (Pandya et al., 2017). As a cell model for system feasibility testing, they used B16-F10 mouse melanoma, 4T1 mouse breast cancer, and DU 145 human prostate cancer cells and treated them with carboplatin or paclitaxel, depending on the cell type.

Except for single anticancer drug testing, microfluidic-based 3D cultures are also suitable for the evaluation of combined drug effects, which represents a common chemotherapeutic approach in cancer treatment. Generally, microfluidic devices for multiple drug applications are designed to generate a concentration gradient of drug combinations, therefore making them useful for the optimization of combination drug treatment. For example, An et al. developed a microfluidic chip that generates 64 different concentration combinations of curcumin and tumor necrosis factor-alpha (TNF $\alpha$ ) related apoptosis-inducing ligand (TRAIL) and tested them on PC3 cells (An et al., 2014). A different design of microfluidic chip was used by Fan et al., to examine the cytotoxic effect of 24 different concentration combinations of pitavastatin and irinotecan against the human glioma U87 cell line (Fan et al., 2016). The same group, in the recent study, improved this brain cancer chip by preventing any drug molecule diffusion between channels. The validity of the new system was tested on glioblastoma patient-derived spheroids with simultaneous exposure to temozolomide and bevacizumab (Akay et al., 2018). Most recently, Khoo and co-authors evaluated the combined effect of doxorubicin and aspirin in eliminating cancer stem cells responsible for chemoresistance (Khoo et al., 2019). They used a microfluidic array with a gradient generator component that mixes drugs and makes various drug concentration combinations.

Microfluidic-based 3D cultures could be also successfully used to evaluate the potential of different compounds to overcome MDR. As previously mentioned, Burić et al., recently reported the sensitization of resistant RC6 cells to temozolomide by its combining with coenzyme Q10 in a 3D microfluidic device with collagen hydrogel (Burić et al., 2019).

\section{Future directions in cancer MDR research}

Future techniques that could explain the complex interaction between resistance mechanisms and TME can help to develop efficient personalized treatment strategies. The use of phenotype-driven $3 \mathrm{D}$ cultures for the investigation of patient-derived biopsies could be optimal for the establishment of the most appropriate in vivo mimicking model. Answering the key question of which cancer patients could benefit from the specific therapeutic regimen, should be prioritized in primary tumors' treatment to avoid the development of metastatic disease. To that end, the construction of biomimetic devices with advanced characteristics may facilitate the precise manipulation of culturing conditions and sustainable maintenance of complex 
environmental milieu. 3D printing and microfabrication can yield scaffolds with various geometries, thus enabling spatial investigation of cancer cells co-cultured with stromal cells embedded in the specific ECM. Importantly, controlled transport of nutrients and oxygen, as well as hormones and growth factors, can provide the establishment of relevant signaling patterns in cancer cells that could not be achieved with traditional 2D culture. Besides, 3D culturing in bioreactors will secure long-term follow-up of cancer progression and treatment efficacy, thus overcoming the problem of inconsistency between the length of tumor growth in patients and tumor growth under in vitro culture conditions. Namely, phenotypic alterations occur during the time in a certain chronology and thus real-time monitoring should replace endpoint analyses. This will further contribute to the development of the organon-chip platform. One of the most successful examples is the tissue engineering of human skin for modeling human melanoma growth (Netzlaff et al., 2005). Even pharmacokinetic studies that have been exclusively performed in animal models were successfully accomplished in devices equipped with channels and chambers enabling culturing of liver, lung and fat cells in interconnected compartments with an exchange of metabolites (Esch et al., 2011). It seems rational that microfluidic devices can be adjusted for high-throughput screenings of patient samples to identify chemoresistant phenotypes and to define the most efficacious treatment regimens. This research direction will certainly favor the understanding of phenotypic changes while intracellular mechanisms could be left aside. Shifting the focus of cancer research that was for many decades directed towards studying complex signaling networks and pathways, may lead to the unravelling of key cancer research mysteries.

On the other hand, heterogeneity among cancer cells calls for their individual analysis to identify resistant and aggressive malignant clones. Heterogeneity increases the likelihood of the development of drug-resistant subpopulations which can be critical for the progression of cancer. The way to achieve the most accurate and efficacious treatment which is the administration of potent drugs to each patient, requires the characterization of cancer cell phenotypes as well as molecular profiles. The recent upgrading and continuous improvement of sophisticated sequencing tools at the single- and multiple-cell level enhance our knowledge about the molecular context of tumor behavior and interaction with its surroundings. Through new sequencing tools deciphering the molecular mechanism, underlying cancer drug resistance can help in the design of more efficient and precise chemo- and radiotherapeutic strategies. Targeted therapies were developed upon the identification of biomarkers derived from primary tumor biopsies subjected to genomic sequencing. In the future, more attention should be given to the disease in its relapsed stage and the utilization of sequencing techniques for the modification of initially used treatment regimens.

It was previously shown that cancer cells exhibit different motility patterns with the ability to shift between an epithelial to mesenchymal (i.e. amoeboid) mode to enable the invasiveness and dissemination of cancer cells (Wolf et al., 2003). Therefore, studying the motility of cancer cells using modern imaging tools can provide additional information about cancer cell behavior in association with 3D platforms. Recently, different AFM models have been created mainly to study the mechanical and dynamic properties of cancer cells (Cartagena-Rivera et al., 2015; Dufrêne et al., 2017; Guan et al., 2017). Coupled with the abovementioned complementary techniques, AFM can help to answer unresolved issues in cancer research including the interplay between drug resistance and metastatic disease. Continuous interest in the development and improvement may give AFM technology an important role in cancer research, diagnosis, and therapeutics.

\section{Declaration of Competing Interest}

Ignacio Ochoa Garrido is promoter and consultant for BeOnChip S.L. and EBERS Medical Technology S.L. (Zaragoza, Spain). Both cited companies have had no role in the decision to publish nor were involved in the writing of this manuscript. Mónica Suárez Korsnes declares that the research was conducted in the absence of any commercial or financial relationships that could be constructed as a potential conflict of interest. She is the owner of the Upstart firm Korsnes Biocomputing (KoBio; https://korsnesbiocomputing.no/) aimed to participate in research and development of methods for single-cell analysis.

\section{Acknowledgements}

This article is based upon work from COST Action CA17104 "New diagnostic and therapeutic tools against multidrug resistant tumors" supported by COST (European Cooperation in Science and Technology) and upon collaboration of Tijana Stanković, Milica Pešić and Ignacio Ochoa Garrido within James S. Mc. Donnell Foundation 21 st Century Science Initiative in Mathematical and Complex Systems Approaches for Brain Cancer (Collaborative award 220020560). Sandor Kasas is funded by the Swiss National Grants200021-144321 and 407240_167137, the Gebert Rüf StiftungGRS-024/14 and NASANNH16ZDA001N-CLDTCH. Tijana Stanković and Milica Pešić are funded by the Ministry of Education, Science and Technological Development, Republic of Serbia (grant No. III41031). Radka Vaclavikova is funded by the Ministry of Education, Youth and Sports (grant INTER-COST No. LTC19020) and the Czech Science Foundation project no. 19-10543S. Ignacio Ochoa Garrido is funded by the Spanish national research program (BIO2016-79092-R) and the European Union's Horizon 2020 research and innovation program (ORCHID and CISTEM projects) under grant agreement No 766884 and 778354 respectively. Authors would like to thank Lorena Ceamanos for her technical support with the figures of this paper.

\section{References}

Agarwal, P., Wang, H., Sun, M., Xu, J., Zhao, S., Liu, Z, Gooch, K.J., Zhao, Y, Lu, X., He, X., 2017. Microfluidics enabled bottom-up engineering of 3D vascularized tumor for drug discovery. ACS Nano 11, 6691-6702.

Akay, M., Hite, J., Avci, N.G., Fan, Y., Akay, Y., Lu, G., Zhu, J.-J., 2018. Drug screening of human GBM spheroids in brain cancer chip. Sci. Rep. 8, 15423.

Akram, S.U., Kannala, J., Eklund, L., Heikkilä, J., 2017. Cell tracking via proposal generation and selection. arXiv Prepr. arXiv1705.03386.

Al-Kofahi, O., Radke, R.J., Goderie, S.K., Shen, Q., Temple, S., Roysam, B., 2006. Automated cell lineage construction: a rapid method to analyze clonal development established with murine neural progenitor cells. Cell Cycle 5, 327-335.

Albitar, A., Ma, W., DeDios, I., Estella, J., Ahn, I., Farooqui, M., Wiestner, A., Albitar, M., 2017. Using high-sensitivity sequencing for the detection of mutations in BTK and PLC $\gamma 2$ genes in cellular and cell-free DNA and correlation with progression in patients treated with BTK inhibitors. Oncotarget 8, 17936-17944.

Aleman, J., Skardal, A., 2019. A multi-site metastasis-on-a-chip microphysiological system for assessing metastatic preference of cancer cells. Biotechnol. Bioeng. 116, 936-944.

Alidjinou, E.K., Deldalle, J., Hallaert, C., Robineau, O., Ajana, F., Choisy, P., Hober, D., Bocket, L., 2017. RNA and DNA Sanger sequencing versus next-generation sequencing for HIV-1 drug resistance testing in treatment-naive patients. J. Antimicrob. Chemother. 72, 2823-2830.

Alonso-Sarduy, L., Roduit, C., Dietler, G., Kasas, S., 2011. Human topoisomerase II-DNA interaction study by using atomic force microscopy. FEBS Lett. 585, 3139-3145.

Alzoubi, S., Brody, L., Rahman, S., Mahul-Mellier, A.-L., Mercado, N., Ito, K., El-Bahrawy, M., Silver, A., Boobis, A., Bell, J.D., Hajji, N., 2016. Synergy between histone deacetylase inhibitors and DNA-damaging agents is mediated by histone deacetylase 2 in colorectal cancer. Oncotarget 7, 44505-44521.

An, D., Kim, K., Kim, J., 2014. Microfluidic system based high throughput drug screening system for curcumin/TRAIL combinational chemotherapy in human prostate cancer PC3 cells. Biomol. Ther. 22, 355-362.

Aref, A.R., Campisi, M., Ivanova, E., Portell, A., Larios, D., Piel, B.P., Mathur, N., Zhou, C., Coakley, R.V., Bartels, A., Bowden, M., Herbert, Z., Hill, S., Gilhooley, S., Carter, J., Cañadas, I., Thai, T.C., Kitajima, S., Chiono, V., Paweletz, C.P., Barbie, D.A., Kamm, R.D., Jenkins, R.W., 2018. 3D microfluidic ex vivo culture of organotypic tumor spheroids to model immune checkpoint blockade. Lab Chip 18, 3129-3143.

Arjumand, W., Asiaf, A., Ahmad, S.T., 2018. Noncoding RNAs in DNA damage response: opportunities for cancer therapeutics. Methods Mol. Biol. 1699, 3-21.

Assaraf, Y.G., Borgnia, M.J., 1994. Probing the interaction of the multidrug-resistance phenotype with the polypeptide ionophore gramicidin D via functional channel formation. Eur. J. Biochem. 222, 813-824.

Ayuso, J.M., Monge, R., Martínez-González, A., Virumbrales-Muñoz, M., Llamazares, 
G.A., Berganzo, J., Hernández-Laín, A., Santolaria, J., Doblaré, M., Hubert, C., Rich, J.N., Sánchez-Gómez, P., Pérez-García, V.M., Ochoa, I., Fernández, L.J., 2017. Glioblastoma on a microfluidic chip: generating pseudopalisades and enhancing aggressiveness through blood vessel obstruction events. Neuro. Oncol. 19, 503-513.

Ayuso, J.M., Virumbrales-Muñoz, M., Lacueva, A., Lanuza, P.M., Checa-Chavarria, E., Botella, P., Fernández, E., Doblare, M., Allison, S.J., Phillips, R.M., Pardo, J., Fernandez, L.J., Ochoa, I., 2016. Development and characterization of a microfluidic model of the tumour microenvironment. Sci. Rep. 6, 36086.

Beermann, J., Piccoli, M.-T., Viereck, J., Thum, T., 2016. Non-coding RNAs in development and disease: background, mechanisms, and therapeutic approaches. Physiol. Rev. 96, 1297-1325.

Berdeu, A., Laperrousaz, B., Bordy, T., Mandula, O., Morales, S., Gidrol, X., PicolletD'hahan, N., Allier, C., 2018. Lens-free microscopy for 3D + time acquisitions of 3D cell culture. Sci. Rep. 8, 16135.

Bereza, W., Szczepanek, J., Laskowska, J., Tretyn, A., 2017. New candidate genes for lack of sensitivity to therapy in pediatric leukemias. Curr. Cancer Drug Targets 17, 333-343.

Binnig, G., Quate, C.F., Gerber, C., 1986. Atomic force microscope. Phys. Rev. Lett. 56, 930-933.

Bolgioni, A.F., Vittoria, M.A., Ganem, N.J., 2018. Long-term live-cell imaging to assess cell fate in response to paclitaxel. J. Vis. Exp.

Boussommier-Calleja, A., Atiyas, Y., Haase, K., Headley, M., Lewis, C., Kamm, R.D., 2019. The effects of monocytes on tumor cell extravasation in a 3D vascularized microfluidic model. Biomaterials 198, 180-193.

Boussommier-Calleja, A., Li, R., Chen, M.B., Wong, S.C., Kamm, R.D., 2016. Microfluidics: a new tool for modeling cancer-immune interactions. Trends Cancer 2, 6-19.

Burić, S.S., Podolski-Renić, A., Dinić, J., Stanković, T., Jovanović, M., Hadžić, S., Ayuso, J.M., Virumbrales-Muñoz, M., Fernández, L.J., Ochoa, I., Pérez-García, V.M., Pešić, M., 2019. Modulation of antioxidant potential with coenzyme Q10 suppressed invasion of temozolomide-resistant rat glioma in vitro and in vivo. Oxid. Med. Cell. Longev. 2019, 3061607.

Caballero, D., Kaushik, S., Correlo, V.M., Oliveira, J.M., Reis, R.L., Kundu, S.C., 2017. Organ-on-chip models of cancer metastasis for future personalized medicine: from chip to the patient. Biomaterials 149, 98-115.

Cappella, B., Dietler, G., 1999. Force-distance curves by atomic force microscopy. Surf. Sci. Rep. 34, 1-104.

Cartagena-Rivera, A.X., Wang, W.-H., Geahlen, R.L., Raman, A., 2015. Fast, multi-frequency, and quantitative nanomechanical mapping of live cells using the atomic force microscope. Sci. Rep. 5, 11692.

Chandana, S., Babiker, H.M., Mahadevan, D., 2019. Therapeutic trends in pancreatic ductal adenocarcinoma (PDAC). Expert Opin. Investig. Drugs 28, 161-177.

Chen, J., Xu, Z.-Y., Wang, F., 2015. Association between DNA methylation and multidrug resistance in human glioma SHG-44 cells. Mol. Med. Rep. 11, 43-52.

Chen, M.B., Whisler, J.A., Fröse, J., Yu, C., Shin, Y., Kamm, R.D., 2017. On-chip human microvasculature assay for visualization and quantification of tumor cell extravasation dynamics. Nat. Protoc. 12, 865-880.

Chen, X., Yang, T., Wang, W., Xi, W., Zhang, T., Li, Q., Yang, A., Wang, T., 2019. Circular RNAs in immune responses and immune diseases. Theranostics 9, 588-607.

Cho, S.-Y., Chae, J., Na, D., Kang, W., Lee, A., Min, S., Kang, J., Choi, B., Lee, J., Sung, C.O., Chuang, J.H., Lee, C., Lee, W.-S., Park, H., Kim, J.-I., 2019. Unstable genome and transcriptome dynamics during tumor metastasis contribute to therapeutic heterogeneity in colorectal cancers. Clin. Cancer Res. 25, 2821-2834.

Conteduca, V., Wetterskog, D., Sharabiani, M.T.A., Grande, E., Fernandez-Perez, M.P., Jayaram, A., Salvi, S., Castellano, D., Romanel, A., Lolli, C., Casadio, V., Gurioli, G., Amadori, D., Font, A., Vazquez-Estevez, S., González Del Alba, A., Mellado, B. Fernandez-Calvo, O., Méndez-Vidal, M.J., Climent, M.A., Duran, I., Gallardo, E., Rodriguez, A., Santander, C., Sáez, M.I., Puente, J., Gasi Tandefelt, D., Wingate, A., Dearnaley, D., PREMIERE Collaborators, F., Spanish Oncology Genitourinary Group, U., Demichelis, F., De Giorgi, U., Gonzalez-Billalabeitia, E., Attard, G., 2017. Androgen receptor gene status in plasma DNA associates with worse outcome on enzalutamide or abiraterone for castration-resistant prostate cancer: a multi-institution correlative biomarker study. Ann. Oncol. Off. J. Eur. Soc. Med. Oncol. 28, 1508-1516.

Cooper, S., Bakal, C., 2017. Accelerating live single-cell signalling studies. Trends Biotechnol. 35, 422-433.

Cooper, S., Barr, A.R., Glen, R., Bakal, C., 2017. NucliTrack: an integrated nuclei tracking application. Bioinformatics 33, 3320-3322.

Corsetto, P.A., Cremona, A., Montorfano, G., Jovenitti, I.E., Orsini, F., Arosio, P., Rizzo, A.M., 2012. Chemical-physical changes in cell membrane microdomains of breast cancer cells after omega-3 PUFA incorporation. Cell Biochem. Biophys. 64, 45-59.

Costa, E.C., Moreira, A.F., de Melo-Diogo, D., Gaspar, V.M., Carvalho, M.P., Correia, I.J., 2016. 3D tumor spheroids: an overview on the tools and techniques used for their analysis. Biotechnol. Adv. 34, 1427-1441.

Costa, V., Aprile, M., Esposito, R., Ciccodicola, A., 2013. RNA-Seq and human complex diseases: recent accomplishments and future perspectives. Eur. J. Hum. Genet. 21, 134-142.

Coussens, L.M., Werb, Z., 2002. Inflammation and cancer. Nature 420, 860-867.

Coutu, D.L., Schroeder, T., 2013. Probing cellular processes by long-term live imaginghistoric problems and current solutions. J. Cell. Sci. 126, 3805-3815.

Crofts, T.S., Gasparrini, A.J., Dantas, G., 2017. Next-generation approaches to understand and combat the antibiotic resistome. Nat. Rev. Microbiol. 15, 422-434.

Cui, Q., Wang, J.-Q., Assaraf, Y.G., Ren, L., Gupta, P., Wei, L., Ashby, C.R., Yang, D.-H., Chen, Z.-S., 2018. Modulating ROS to overcome multidrug resistance in cancer. Drug Resist. Updat. 41, 1-25.

Davis, P.J., Kosmacek, E.A., Sun, Y., Ianzini, F., Mackey, M.A., 2007. The large-scale digital cell analysis system: an open system for nonperturbing live cell imaging. J.
Microsc. 228, 296-308

De Laere, B., van Dam, P.-J., Whitington, T., Mayrhofer, M., Diaz, E.H., Van den Eynden, G., Vandebroek, J., Del-Favero, J., Van Laere, S., Dirix, L., Grönberg, H., Lindberg, J., 2017. Comprehensive profiling of the androgen receptor in liquid biopsies from castration-resistant prostate cancer reveals novel Intra-AR structural variation and splice variant expression patterns. Eur. Urol. 72, 192-200.

Ding, Y., Cheng, Y., Sun, Q., Zhang, Y., You, K., Guo, Y., Han, D., Geng, L., 2015. Mechanical characterization of cervical squamous carcinoma cells by atomic force microscopy at nanoscale. Med. Oncol. 32, 71.

Du, Z., Mi, S., Yi, X., Xu, Y., Sun, W., 2018. Microfluidic system for modelling 3D tumour invasion into surrounding stroma and drug screening. Biofabrication 10, 34102.

Dufrêne, Y.F., Ando, T., Garcia, R., Alsteens, D., Martinez-Martin, D., Engel, A., Gerber, C., Müller, D.J., 2017. Imaging modes of atomic force microscopy for application in molecular and cell biology. Nat. Nanotechnol. 12, 295-307.

Errington, R.J., Marquez, N., Chappell, S.C., Wiltshire, M., Smith, P.J., 2005. Time-lapse microscopy approaches to track cell cycle progression at the single-cell level. Curr. Protoc. Cytom Chapter 12, Unit 12.4.

Esch, M.B., King, T.L., Shuler, M.L., 2011. The role of body-on-a-chip devices in drug and toxicity studies. Annu. Rev. Biomed. Eng. 13, 55-72.

Fan, Y., Nguyen, D.T., Akay, Y., Xu, F., Akay, M., 2016. Engineering a brain Cancer chip for high-throughput drug screening. Sci. Rep. 6, 25062.

Fang, Q., Chen, X., Zhi, X., 2016. Long non-coding RNA (LncRNA) urothelial carcinoma associated 1 (UCA1) increases multi-drug resistance of gastric Cancer via downregulating miR-27b. Med. Sci. Monit. 22, 3506-3513.

Fu, F., Nowak, M.A., Bonhoeffer, S., 2015. Spatial heterogeneity in drug concentrations can facilitate the emergence of resistance to cancer therapy. PLoS Comput. Biol. 11, e1004142.

Galasso, M., Costantino, G., Pasquali, L., Minotti, L., Baldassari, F., Corrà, F., Agnoletto, C., Volinia, S., 2016. Profiling of the predicted circular RNAs in ductal in situ and invasive breast cancer: a pilot study. Int. J. Genomics 2016, 4503840.

Gascoigne, K.E., Taylor, S.S., 2008. Cancer cells display profound intra- and interline variation following prolonged exposure to antimitotic drugs. Cancer Cell 14, 111-122.

Gautam, S.S., Kc, R., Leong, K.W., Mac Aogáin, M., O’Toole, R.F., 2019. A step-by-step beginner's protocol for whole genome sequencing of human bacterial pathogens. J. Biol. Methods 6, e110.

Gebert, L.F.R., MacRae, I.J., 2019. Regulation of microRNA function in animals. Nat. Rev. Mol. Cell Biol. 20, 21-37.

Germain, T., Ansari, M., Pappas, D., 2016. Observation of reversible, rapid changes in drug susceptibility of hypoxic tumor cells in a microfluidic device. Anal. Chim. Acta 936, 179-184.

Gheibi, P., Zeng, S., Son, K.J., Vu, T., Ma, A.H., Dall'Era, M.A., Yap, S.A., De Vere White, R.W., Pan, C.X., Revzin, A., 2017. Microchamber cultures of bladder cancer: a platform for characterizing drug responsiveness and resistance in PDX and primary cancer cells. Sci. Rep. 7, 12277.

Goff, D.J., Court Recart, A., Sadarangani, A., Chun, H.-J., Barrett, C.L., Krajewska, M., Leu, H., Low-Marchelli, J., Ma, W., Shih, A.Y., Wei, J., Zhai, D., Geron, I., Pu, M., Bao, L., Chuang, R., Balaian, L., Gotlib, J., Minden, M., Martinelli, G., Rusert, J., Dao, K. H., Shazand, K., Wentworth, P., Smith, K.M., Jamieson, C.A.M., Morris, S.R., Messer, K., Goldstein, L.S.B., Hudson, T.J., Marra, M., Frazer, K.A., Pellecchia, M., Reed, J.C., Jamieson, C.H.M., 2013. A Pan-BCL2 inhibitor renders bone-marrow-resident human leukemia stem cells sensitive to tyrosine kinase inhibition. Cell Stem Cell 12, 316-328.

Goler-Baron, V., Assaraf, Y.G., 2011. Structure and function of ABCG2-rich extracellular vesicles mediating multidrug resistance. PLoS One 6, e16007.

Goler-Baron, V., Sladkevich, I., Assaraf, Y.G., 2012. Inhibition of the PI3K-Akt signaling pathway disrupts ABCG2-rich extracellular vesicles and overcomes multidrug resistance in breast cancer cells. Biochem. Pharmacol. 83, 1340-1348.

Gómez-Villafuertes, R., Paniagua-Herranz, L., Gascon, S., de Agustín-Durán, D., Ferreras, M., de la, O., Gil-Redondo, J.C., Queipo, M.J., Menendez-Mendez, A., Pérez-Sen, R., Delicado, E.G., Gualix, J., Costa, M.R., Schroeder, T., Miras-Portugal, M.T., Ortega, F., 2017. Live imaging followed by single cell tracking to monitor cell biology and the lineage progression of multiple neural populations. J. Vis. Exp.

Gov, E., Kori, M., Arga, K.Y., 2017. RNA-based ovarian cancer research from "a gene to systems biomedicine” perspective. Syst. Biol. Reprod. Med. 63, 219-238.

Guan, D., Charlaix, E., Qi, R.Z., Tong, P., 2017. Noncontact viscoelastic imaging of living cells using a long-needle atomic force microscope with dual-frequency modulation. Phys. Rev. Appl. 8, 044010.

Haase, K., Kamm, R.D., 2017. Advances in on-chip vascularization. Regen. Med. 12 285-302.

Hachey, S.J., Hughes, C.C.W., 2018. Applications of tumor chip technology. Lab Chip 18, 2893-2912.

Hadjadj, L., Baron, S.A., Diene, S.M., Rolain, J.-M., 2019. How to discover new antibiotic resistance genes? Expert Rev. Mol. Diagn. 19, 349-362.

Hammond, W.A., Swaika, A., Mody, K., 2016. Pharmacologic resistance in colorectal cancer: a review. Ther. Adv. Med. Oncol. 8, 57-84.

Han, J., Jun, Y., Kim, S.H., Hoang, H.-H., Jung, Y., Kim, S., Kim, J., Austin, R.H., Lee, S., Park, S., 2016. Rapid emergence and mechanisms of resistance by U87 glioblastoma cells to doxorubicin in an in vitro tumor microfluidic ecology. Proc. Natl. Acad. Sci. $113,14283-14288$.

Hanahan, D., Weinberg, R.A., 2000. The hallmarks of cancer. Cell 100, 57-70.

Hanahan, D., Weinberg, R.A., 2011. Hallmarks of cancer: the next generation. Cell 144, 646-674.

Hao, S., Ha, L., Cheng, G., Wan, Y., Xia, Y., Sosnoski, D.M., Mastro, A.M., Zheng, S.-Y., 2018. A spontaneous 3D bone-on-a-chip for bone metastasis study of breast cancer cells. Small 14, e1702787. 
Hassell, B.A., Goyal, G., Lee, E., Sontheimer-Phelps, A., Levy, O., Chen, C.S., Ingber, D.E., 2017. Human organ chip models recapitulate orthotopic lung cancer growth, therapeutic responses, and tumor dormancy in vitro. Cell Rep. 21, 508-516.

Hearn, J.M., Hughes, G.M., Romero-Canelón, I., Munro, A.F., Rubio-Ruiz, B., Liu, Z., Carragher, N.O., Sadler, P.J., 2018. Pharmaco-genomic investigations of organo-iridium anticancer complexes reveal novel mechanism of action. Metallomics 10, 93-107.

Hilsenbeck, O., Schwarzfischer, M., Skylaki, S., Schauberger, B., Hoppe, P.S., Loeffler, D., Kokkaliaris, K.D., Hastreiter, S., Skylaki, E., Filipczyk, A., Strasser, M., Buggenthin, F., Feigelman, J.S., Krumsiek, J., van den Berg, A.J.J., Endele, M., Etzrodt, M., Marr, C., Theis, F.J., Schroeder, T., 2016. Software tools for single-cell tracking and quantification of cellular and molecular properties. Nat. Biotechnol. 34, 703-706.

Hitomi, Y., Tokunaga, K., 2017. Significance of functional disease-causal/susceptible variants identified by whole-genome analyses for the understanding of human diseases. Proc. Japan Acad. Ser. B 93, 657-676.

Hlavac, V., Kovacova, M., Elsnerova, K., Brynychova, V., Kozevnikovova, R., Raus, K., Kopeckova, K., Mestakova, S., Vrana, D., Gatek, J., Ostasov, P., Vaclavikova, R., Soucek, P., 2018. Use of germline genetic variability for prediction of chemoresistance and prognosis of breast cancer patients. Cancers (Basel) 10, E511.

Hoarau-Véchot, J., Rafii, A., Touboul, C., Pasquier, J., 2018. Halfway between 2D and animal models: are 3D cultures the ideal tool to study cancer-microenvironment interactions? Int. J. Mol. Sci. 19, E181.

Hormoz, S., Singer, Z.S., Linton, J.M., Antebi, Y.E., Shraiman, B.I., Elowitz, M.B., 2016 Inferring cell-state transition dynamics from lineage trees and endpoint single-cell measurements. Cell Syst. 3, 419-433 e8.

Hsiao, K.-Y., Sun, H.S., Tsai, S.-J., 2017. Circular RNA - New member of noncoding RNA with novel functions. Exp. Biol. Med. (Maywood) 242, 1136-1141.

Hu, S., Chen, Y., Wang, Z.-F., Mao-Ying, Q.-L., Mi, W.-L., Jiang, J.-W., Wu, G.-C., Wang, Y.-Q., 2015. The analgesic and antineuroinflammatory effect of Baicalein in cancerinduced bone pain. Evid. Based Complement. Alternat. Med. 2015, 973524.

Huang, C., Jin, H., Song, B., Zhu, X., Zhao, H., Cai, J., Lu, Y., Chen, B., Lin, Y., 2012. The cytotoxicity and anticancer mechanisms of alterporriol L, a marine bianthraquinone, against MCF-7 human breast cancer cells. Appl. Microbiol. Biotechnol. 93, 777-785.

Huang, X., Li, Z., Zhang, Q., Wang, W., Li, B., Wang, Lu, Xu, Zhipeng, Zeng, A., Zhang, Xing, Zhang, Xuan, He, Z., Li, Qiang, Sun, G., Wang, S., Li, Qing, Wang, Linjun, Zhang, L., Xu, H., Xu, Zekuan, 2019. Circular RNA AKT3 upregulates PIK3R1 to enhance cisplatin resistance in gastric cancer via miR-198 suppression. Mol. Cancer $18,71$.

Huda, S., Weigelin, B., Wolf, K., Tretiakov, K.V., Polev, K., Wilk, G., Iwasa, M., Emami, F.S., Narojczyk, J.W., Banaszak, M., Soh, S., Pilans, D., Vahid, A., Makurath, M., Friedl, P., Borisy, G.G., Kandere-Grzybowska, K., Grzybowski, B.A., 2018. Lévy-like movement patterns of metastatic cancer cells revealed in microfabricated systems and implicated in vivo. Nat. Commun. 9, 4539.

Huth, J., Buchholz, M., Kraus, J.M., Schmucker, M., von Wichert, G., Krndija, D., Seufferlein, T., Gress, T.M., Kestler, H.A., 2010. Significantly improved precision of cell migration analysis in time-lapse video microscopy through use of a fully automated tracking system. BMC Cell Biol. 11, 24.

Ifergan, I., Scheffer, G.L., Assaraf, Y.G., 2005. Novel extracellular vesicles mediate an ABCG2-dependent anticancer drug sequestration and resistance. Cancer Res. 65, 10952-10958.

Ip, C.K.M., Li, S.S., Tang, M.Y.H., Sy, S.K.H., Ren, Y., Shum, H.C., Wong, A.S.T., 2016 Stemness and chemoresistance in epithelial ovarian carcinoma cells under shear stress. Sci. Rep. 6, 26788

Jan, A.T., Rahman, S., Khan, S., Tasduq, S.A., Choi, I., 2019. Biology, pathophysiological role, and clinical implications of exosomes: a critical appraisal. Cells 8, 99.

Jeong, S.Y., Lee, J.H., Shin, Y., Chung, S., Kuh, H.J., 2016. Co-culture of tumor spheroids and fibroblasts in a collagen matrix-incorporated microfluidic chip mimics reciprocal activation in solid tumor microenvironment. PLoS One 11, e0159013.

Jia, B., Liu, W., Gu, J., Wang, J., Lv, W., Zhang, Wangqian, Hao, Q., Pang, Z., Mu, N., Zhang, Wei, Guo, Q., 2019. MiR-7-5p suppresses stemness and enhances temozolomide sensitivity of drug-resistant glioblastoma cells by targeting Yin Yang 1. Exp. Cell Res. 375, 73-81.

Jiang, T., Shi, W., Natowicz, R., Ononye, S.N., Wali, V.B., Kluger, Y., Pusztai, L., Hatzis, C., 2014. Statistical measures of transcriptional diversity capture genomic heterogeneity of cancer. BMC Genomics 15, 876.

Jo, Y., Choi, N., Kim, H.N., Choi, J., 2018. Probing characteristics of cancer cells cultured on engineered platforms simulating different microenvironments. Artif. Cells, Nanomedicine Biotechnol. 46, S1170-S1179.

Junttila, M.R., de Sauvage, F.J., 2013. Influence of tumour micro-environment heterogeneity on therapeutic response. Nature 501, 346-354.

Kadioglu, O., Cao, J., Kosyakova, N., Mrasek, K., Liehr, T., Efferth, T., 2016. Genomic and transcriptomic profiling of resistant CEM/ADR-5000 and sensitive CCRF-CEM leukaemia cells for unravelling the full complexity of multi-factorial multidrug resistance. Sci. Rep. 6, 36754 .

Kasas, S., Dietler, G., 2008. Probing nanomechanical properties from biomolecules to living cells. Pflugers Arch. 456, 13-27.

Kasas, S., Stupar, P., Longo, G., Dietler, G., 2015. [Detecting life thanks to the atomic force microscope]. Med. Sci. (Paris) 31, 369-371.

Kasas, S., Wang, X., Hirling, H., Marsault, R., Huni, B., Yersin, A., Regazzi, R., Grenningloh, G., Riederer, B., Forrò, L., Dietler, G., Catsicas, S., 2005. Superficial and deep changes of cellular mechanical properties following cytoskeleton disassembly. Cell Motil. Cytoskeleton 62, 124-132.

Khan, I.A., Husemann, P., Campbell, L., White, N.S., White, R.J., Smith, P.J., Errington, R.J., 2007. ProgeniDB: a novel cell lineage database for generation associated phenotypic behavior in cell-based assays. Cell Cycle 6, 868-874.

Khoo, B.L., Grenci, G., Lim, J.S.Y., Lim, Y.P., Fong, J., Yeap, W.H., Bin Lim, S., Chua, S.L.,
Wong, S.C., Yap, Y.S., Lee, S.C., Lim, C.T., Han, J., 2019. Low-dose anti-inflammatory combinatorial therapy reduced cancer stem cell formation in patient-derived preclinical models for tumour relapse prevention. Br. J. Cancer 120, 407-423.

Kim, C., Kasuya, J., Jeon, J., Chung, S., Kamm, R.D., 2015. A quantitative microfluidic angiogenesis screen for studying anti-angiogenic therapeutic drugs. Lab Chip 15, 301-310.

Koh, S.-B., Mascalchi, P., Rodriguez, E., Lin, Y., Jodrell, D.I., Richards, F.M., Lyons, S.K., 2017. A quantitative FastFUCCI assay defines cell cycle dynamics at a single-cell level. J. Cell. Sci. 130, 512-520.

Kon, E., Benhar, I., 2019. Immune checkpoint inhibitor combinations: current efforts and important aspects for success. Drug Resist. Updat. 45, 13-29.

Kong, Y., Bai, P.-S., Sun, H., Nan, K.-J., Chen, N.-Z., Qi, X.-G., 2012. The deoxycholic acid targets miRNA-dependent CAC1 gene expression in multidrug resistance of human colorectal cancer. Int. J. Biochem. Cell Biol. 44, 2321-2332.

Koo, H., Park, I., Lee, Y., Kim, H.J., Jung, J.H., Lee, J.H., Kim, Y., Kim, J.-H., Park, J.W., 2016. Visualization and quantification of MicroRNA in a single cell using atomic force microscopy. J. Am. Chem. Soc. 138, 11664-11671.

Korsnes, M.S., Korsnes, R., 2015. Lifetime distributions from tracking individual BC3H1 cells subjected to yessotoxin. Front. Bioeng. Biotechnol. 3, 166.

Korsnes, M.S., Korsnes, R., 2017. Mitotic catastrophe in BC3H1 cells following yessotoxin exposure. Front. Cell Dev. Biol. 5, 30.

Korsnes, M.S., Korsnes, R., 2018. Single-cell tracking of A549 lung Cancer cells exposed to a marine toxin reveals correlations in pedigree tree profiles. Front. Oncol. 8, 260.

Kumar, S., Talluri, S., Pal, J., Yuan, X., Lu, R., Nanjappa, P., Samur, M.K., Munshi, N.C., Shammas, M.A., 2018. Role of apurinic/apyrimidinic nucleases in the regulation of homologous recombination in myeloma: mechanisms and translational significance. Blood Cancer J. 8, 92.

Kun-Peng, Z., Xiao-Long, M., Lei, Z., Chun-Lin, Z., Jian-Ping, H., Tai-Cheng, Z., 2018. Screening circular RNA related to chemotherapeutic resistance in osteosarcoma by RNA sequencing. Epigenomics 10, 1327-1346.

Kyrochristos, I.D., Ziogas, D.E., Roukos, D.H., 2019. Dynamic genome and transcriptional network-based biomarkers and drugs: precision in breast cancer therapy. Med. Res. Rev. 39, 1205-1227.

Lammens, T., Durinck, K., Wallaert, A., Speleman, F., Van Vlierberghe, P., 2017. Long non-coding RNAs in leukemia. Curr. Opin. Hematol. 24, 353-358.

Lancaster, O.M., Le Berre, M., Dimitracopoulos, A., Bonazzi, D., Zlotek-Zlotkiewicz, E., Picone, R., Duke, T., Piel, M., Baum, B., 2013. Mitotic rounding alters cell geometry to ensure efficient bipolar spindle formation. Dev. Cell 25, 270-283.

Lang, J.D., Berry, S.M., Powers, G.L., Beebe, D.J., Alarid, E.T., 2013. Hormonally responsive breast cancer cells in a microfluidic co-culture model as a sensor of microenvironmental activity. Integr. Biol. (Camb) 5, 807-816.

Lee, E., Song, H.-H.G., Chen, C.S., 2016. Biomimetic on-a-chip platforms for studying cancer metastasis. Curr. Opin. Chem. Eng. 11, 20-27.

Lee, H., Park, W., Ryu, H., Jeon, N.L., 2014. A microfluidic platform for quantitative analysis of cancer angiogenesis and intravasation. Biomicrofluidics 8, 054102

Lekka, M., 2016. Discrimination between normal and cancerous cells using AFM. Bionanoscience 6, 65-80.

Leonetti, A., Assaraf, Y.G., Veltsista, P.D., El Hassouni, B., Tiseo, M., Giovannetti, E., 2019. MicroRNAs as a drug resistance mechanism to targeted therapies in EGFRmutated NSCLC: current implications and future directions. Drug Resist. Updat. 42, $1-11$.

Li, L., Li, Y., Shao, Z., Luo, G., Ding, M., Liang, Q., 2018. Simultaneous assay of oxygendependent cytotoxicity and genotoxicity of anticancer drugs on an integrated microchip. Anal. Chem. 90, 11899-11907.

Li, Ming-hui, Fu, S., Xiao, H., 2015a. Genome-wide analysis of microRNA and mRNA expression signatures in cancer. Acta Pharmacol. Sin. 36, 1200-1211.

Li, Mi, Liu, L., Xi, N., Wang, Y., Xiao, X., Zhang, W., 2015b. Quantitative analysis of drug induced complement-mediated cytotoxic effect on single tumor cells using atomic force microscopy and fluorescence microscopy. IEEE Trans. Nanobioscience 14 84-94.

Li, M., Xiao, X., Liu, L., Xi, N., Wang, Y., 2016a. Nanoscale quantifying the effects of targeted drug on chemotherapy in lymphoma treatment using atomic force microscopy. IEEE Trans. Biomed. Eng. 63, 2187-2199.

Li, W., Zhang, H., Assaraf, Y.G., Zhao, K., Xu, X., Xie, J., Yang, D.-H., Chen, Z.-S., 2016b. Overcoming ABC transporter-mediated multidrug resistance: molecular mechanisms and novel therapeutic drug strategies. Drug Resist. Updat. 27, 14-29.

Liang, H., Xu, Y., Zhang, Q., Yang, Y., Mou, Y., Gao, Y., Chen, R., Chen, C., Dai, P., 2019. MiR-483-3p regulates oxaliplatin resistance by targeting FAM171B in human colorectal cancer cells. Artif. cells, nanomedicine, Biotechnol. 47, 725-736.

Liang, X., Qi, M., Wu, R., Liu, A., Chen, D., Tang, L., Chen, J., Hu, X., Li, W., Zhan, L., Shao, C., 2018. Long non-coding RNA CUDR promotes malignant phenotypes in pancreatic ductal adenocarcinoma via activating AKT and ERK signaling pathways. Int. J. Oncol. 53, 2671-2682.

Lim, W., Park, S., 2018. A microfluidic spheroid culture device with a concentration gradient generator for high-throughput screening of drug efficacy. Molecules 23, 3355.

Lin, K., Torga, G., Wu, A., Rabinowitz, J.D., Murray, W.J., Sturm, J.C., Pienta, K.J., Austin, R., 2017a. Dynamics on a complex drug landscape. Converg. Sci. Phys. Oncol. 3 pii: 045001.

Lin, K.C., Torga, G., Sun, Y., Axelrod, R., Pienta, K.J., Sturm, J.C., Austin, R.H., 2019. The role of heterogeneous environment and docetaxel gradient in the emergence of polyploid, mesenchymal and resistant prostate cancer cells. Clin. Exp. Metastasis 36, 97-108.

Lin, L., Lin, X., Lin, Luyao, Feng, Q., Kitamori, T., Lin, J.M., Sun, J., 2017b. Integrated microfluidic platform with multiple functions to probe tumor-endothelial cell interaction. Anal. Chem. 89, 10037-10044. 
Livney, Y.D., Assaraf, Y.G., 2013. Rationally designed nanovehicles to overcome cancer chemoresistance. Adv. Drug Deliv. Rev. 65, 1716-1730.

Longo, G., Alonso-Sarduy, L., Rio, L.M., Bizzini, A., Trampuz, A., Notz, J., Dietler, G., Kasas, S., 2013. Rapid detection of bacterial resistance to antibiotics using AFM cantilevers as nanomechanical sensors. Nat. Nanotechnol. 8, 522-526.

López-Jiménez, E., Rojas, A.M., Andrés-León, E., 2018. RNA sequencing and prediction tools for circular RNAs analysis. Adv. Exp. Med. Biol. 1087, 17-33.

Lujambio, A., Lowe, S.W., 2012. The microcosmos of cancer. Nature 482, 347-355.

Ma, L., Wang, R., Duan, H., Nan, Y., Wang, Q., Jin, F., 2015. Mitochondrial dysfunction rather than mtDNA sequence mutation is responsible for the multi-drug resistance of small cell lung cancer. Oncol. Rep. 34, 3238-3246.

Mao, P., Joshi, K., Li, J., Kim, S.-H., Li, P., Santana-Santos, L., Luthra, S., Chandran, U.R., Benos, P.V., Smith, L., Wang, M., Hu, B., Cheng, S.-Y., Sobol, R.W., Nakano, I., 2013. Mesenchymal glioma stem cells are maintained by activated glycolytic metabolism involving aldehyde dehydrogenase 1A3. Proc. Natl. Acad. Sci. 110, 8644-8649.

Marinov, G.K., 2017. On the design and prospects of direct RNA sequencing. Brief. Funct. Genomics 16, 326-335.

Martincorena, I., Raine, K.M., Gerstung, M., Dawson, K.J., Haase, K., Van Loo, P., Davies, H., Stratton, M.R., Campbell, P.J., 2017. Universal patterns of selection in Cancer and somatic tissues. Cell 171, 1029-1041 e21.

Marusyk, A., Polyak, K., 2010. Tumor heterogeneity: causes and consequences. Biochim. Biophys. Acta 1805, 105-117.

Masoud, V., Pagès, G., 2017. Targeted therapies in breast cancer: new challenges to fight against resistance. World J. Clin. Oncol. 8, 120-134.

May, M., Denecke, B., Schroeder, T., Götz, M., Faissner, A., 2018. Cell tracking in vitro reveals that the extracellular matrix glycoprotein Tenascin-C modulates cell cycle length and differentiation in neural stem/progenitor cells of the developing mouse spinal cord. Biol. Open 7 pii: bio027730.

McGranahan, N., Swanton, C., 2017. Clonal heterogeneity and tumor evolution: past, present, and the future. Cell 168, 613-628.

Meijering, E., Dzyubachyk, O., Smal, I., 2012. Methods for cell and particle tracking. Methods Enzymol. 504, 183-200.

Metzker, M.L., 2010. Sequencing technologies — the next generation. Nat. Rev. Genet. $11,31-46$.

Mi, S., Liu, Z., Du, Z., Yi, X., Sun, W., 2019. Three-dimensional microfluidic tumor-macrophage system for breast cancer cell invasion. Biotechnol. Bioeng. 1-11.

Mikhaylenko, D.S., Alekseev, B.Y., Zaletaev, D.V., Goncharova, R.I., Nemtsova, M.V., 2018. Structural alterations in human fibroblast growth factor receptors in carcinogenesis. Biochemistry (Mosc) 83, 930-943.

Milan, A., Leal-Taixé, L., Reid, I., Roth, S., Schindler, K., 2016. MOT16: A benchmark for multi-object tracking. arXiv Prepr. arXiv 1603.00831.

Moore, N., Doty, D., Zielstorff, M., Kariv, I., Moy, L.Y., Gimbel, A., Chevillet, J.R., Lowry, N., Santos, J., Mott, V., Kratchman, L., Lau, T., Addona, G., Chen, H., Borenstein, J.T., 2018. A multiplexed microfluidic system for evaluation of dynamics of immune-tumor interactions. Lab Chip 18, 1844-1858.

Moussy, A., Cosette, J., Parmentier, R., da Silva, C., Corre, G., Richard, A., Gandrillon, O., Stockholm, D., Páldi, A., 2017. Integrated time-lapse and single-cell transcription studies highlight the variable and dynamic nature of human hematopoietic cell fate commitment. PLoS Biol. 15, e2001867.

Nahar, R., Zhai, W., Zhang, T., Takano, A., Khng, A.J., Lee, Y.Y., Liu, X., Lim, C.H., Koh, T.P.T., Aung, Z.W., Lim, T.K.H., Veeravalli, L., Yuan, J., Teo, A.S.M., Chan, C.X., Poh, H.M., Chua, I.M.L., Liew, A.A., Lau, D.P.X., Kwang, X.L., Toh, C.K., Lim, W.-T., Lim, B., Tam, W.L., Tan, E.-H., Hillmer, A.M., Tan, D.S.W., 2018. Elucidating the genomic architecture of Asian EGFR-mutant lung adenocarcinoma through multi-region exome sequencing. Nat. Commun. 9, 216.

Netzlaff, F., Lehr, C.-M., Wertz, P.W., Schaefer, U.F., 2005. The human epidermis models EpiSkin, SkinEthic and EpiDerm: an evaluation of morphology and their suitability for testing phototoxicity, irritancy, corrosivity, and substance transport. Eur. J. Pharm. Biopharm. 60, 167-178.

Ng, W.L., Mohd Mohidin, T.B., Shukla, K., 2018. Functional role of circular RNAs in cancer development and progression. RNA Biol. 15, 995-1005.

Nguyen, M., De Ninno, A., Mencattini, A., Mermet-Meillon, F., Fornabaio, G., Evans, S.S., Cossutta, M., Khira, Y., Han, W., Sirven, P., Pelon, F., Di Giuseppe, D., Bertani, F.R., Gerardino, A., Yamada, A., Descroix, S., Soumelis, V., Mechta-Grigoriou, F., Zalcman, G., Camonis, J., Martinelli, E., Businaro, L., Parrini, M.C., 2018. Dissecting effects of anti-cancer drugs and cancer-associated fibroblasts by on-chip reconstitution of immunocompetent tumor microenvironments. Cell Rep. 25, 3884-3893 e3.

Nigita, G., Marceca, G.P., Tomasello, L., Distefano, R., Calore, F., Veneziano, D., Romano, G., Nana-Sinkam, S.P., Acunzo, M., Croce, C.M., 2019. ncRNA editing: functional characterization and computational resources. Methods Mol. Biol. 1912, 133-174.

Ostrow, S.L., Barshir, R., DeGregori, J., Yeger-Lotem, E., Hershberg, R., 2014. Cancer evolution is associated with pervasive positive selection on globally expressed genes. PLoS Genet. 10, e1004239.

Ozcelikkale, A., Shin, K., Noe-Kim, V., Elzey, B.D., Dong, Z., Zhang, J.-T., Kim, K., Kwon, I.C., Park, K., Han, B., 2017. Differential response to doxorubicin in breast Cancer subtypes simulated by a microfluidic tumor model. J. Control. Release 266, 129-139.

Pampaloni, F., Reynaud, E.G., Stelzer, E.H.K., 2007. The third dimension bridges the gap between cell culture and live tissue. Nat. Rev. Mol. Cell Biol. 8, 839-845.

Pandya, H.J., Dhingra, K., Prabhakar, D., Chandrasekar, V., Natarajan, S.K., Vasan, A.S., Kulkarni, A., Shafiee, H., 2017. A microfluidic platform for drug screening in a 3D cancer microenvironment. Biosens. Bioelectron. 94, 632-642.

Pang, L., Liu, W., Tian, C., Xu, J., Li, T., Chen, S., Wang, J., 2016. Construction of singlecell arrays and assay of cell drug-resistance in an integrated microfluidics. Lab Chip.

Pardoll, D.M., 2012. The blockade of immune checkpoints in cancer immunotherapy. Nat. Rev. Cancer 12, 252-264.

Parker, J., Chen, J., 2017. Application of next generation sequencing for the detection of human viral pathogens in clinical specimens. J. Clin. Virol. 86, 20-26.

Patel, D., Gao, Y., Son, K., Siltanen, C., Neve, R.M., Ferrara, K., Revzin, A., 2015. Microfluidic co-cultures with hydrogel-based ligand trap to study paracrine signals giving rise to cancer drug resistance. Lab Chip 15, 4614-4624.

Patra, B., Peng, C.C., Liao, W.H., Lee, C.H., Tung, Y.C., 2016. Drug testing and flow cytometry analysis on a large number of uniform sized tumor spheroids using a microfluidic device. Sci. Rep. 6, 21061.

Pavesi, A., Tan, A.T., Koh, S., Chia, A., Colombo, M., Antonecchia, E., Miccolis, C., Ceccarello, E., Adriani, G., Raimondi, M.T., Kamm, R.D., Bertoletti, A., 2017. A 3D microfluidic model for preclinical evaluation of TCR-engineered T cells against solid tumors. JCI Insight 2 pii: 89762.

Piltti, K.M., Cummings, B.J., Carta, K., Manughian-Peter, A., Worne, C.L., Singh, K., Ong, D., Maksymyuk, Y., Khine, M., Anderson, A.J., 2018. Live-cell time-lapse imaging and single-cell tracking of in vitro cultured neural stem cells - Tools for analyzing dynamics of cell cycle, migration, and lineage selection. Methods 133, 81-90.

Plodinec, M., Loparic, M., Monnier, C.A., Obermann, E.C., Zanetti-Dallenbach, R., Oertle, P., Hyotyla, J.T., Aebi, U., Bentires-Alj, M., Lim, R.Y.H., Schoenenberger, C.-A., 2012. The nanomechanical signature of breast cancer. Nat. Nanotechnol. 7, 757-765.

Portillo-Lara, R., Annabi, N., 2016. Microengineered cancer-on-a-chip platforms to study the metastatic microenvironment. Lab Chip 16, 4063-4081.

Pradhan, S., Smith, A.M., Garson, C.J., Hassani, I., Seeto, W.J., Pant, K., Arnold, R.D., Prabhakarpandian, B., Lipke, E.A., 2018. A microvascularized tumor-mimetic platform for assessing anti-cancer drug efficacy. Sci. Rep. 8, 1-15.

Precone, V., Del Monaco, V., Esposito, M.V., De Palma, F.D.E., Ruocco, A., Salvatore, F., D'Argenio, V., 2015. Cracking the code of human diseases using next-generation sequencing: applications, challenges, and perspectives. Biomed Res. Int. 2015, 161648.

Pritchard, J.R., Lauffenburger, D.A., Hemann, M.T., 2012. Understanding resistance to combination chemotherapy. Drug Resist. Updat. 15, 249-257.

Prusty, D.K., Adam, V., Zadegan, R.M., Irsen, S., Famulok, M., 2018. Supramolecular aptamer nano-constructs for receptor-mediated targeting and light-triggered release of chemotherapeutics into cancer cells. Nat. Commun. 9, 535.

Puig, P.-E., Guilly, M.-N., Bouchot, A., Droin, N., Cathelin, D., Bouyer, F., Favier, L., Ghiringhelli, F., Kroemer, G., Solary, E., Martin, F., Chauffert, B., 2008. Tumor cells can escape DNA-damaging cisplatin through DNA endoreduplication and reversible polyploidy. Cell Biol. Int. 32, 1031-1043.

Raaijmakers, M.I.G., Widmer, D.S., Narechania, A., Eichhoff, O., Freiberger, S.N., Wenzina, J., Cheng, P.F., Mihic-Probst, D., Desalle, R., Dummer, R., Levesque, M.P., 2016. Co-existence of BRAF and NRAS driver mutations in the same melanoma cells results in heterogeneity of targeted therapy resistance. Oncotarget 7, 77163-77174.

Rabbani, B., Nakaoka, H., Akhondzadeh, S., Tekin, M., Mahdieh, N., 2016. Next generation sequencing: implications in personalized medicine and pharmacogenomics. Mol. Biosyst. 12, 1818-1830.

Rahbarghazi, R., Jabbari, N., Sani, N.A., Asghari, R., Salimi, L., Kalashani, S.A., Feghhi, M., Etemadi, T., Akbariazar, E., Mahmoudi, M., Rezaie, J., 2019. Tumor-derived extracellular vesicles: reliable tools for Cancer diagnosis and clinical applications. Cell Commun. Signal 17, 73.

Ramanathan, B., Jindal, H.M., Le, C.F., Gudimella, R., Anwar, A., Razali, R., PooleJohnson, J., Manikam, R., Sekaran, S.D., 2017. Next generation sequencing reveals the antibiotic resistant variants in the genome of Pseudomonas aeruginosa. PLoS One 12 , e0182524.

Rapoport, D.H., Becker, T., Madany Mamlouk, A., Schicktanz, S., Kruse, C., 2011. A novel validation algorithm allows for automated cell tracking and the extraction of biologically meaningful parameters. PLoS One 6, e27315.

Rempfler, M., Stierle, V., Ditzel, K., Kumar, S., Paulitschke, P., Andres, B., Menze, B.H., 2018. Tracing cell lineages in videos of lens-free microscopy. Med. Image Anal. 48, $147-161$.

Ren, J., Huang, H., Liu, Y., Zheng, X., Zou, Q., 2015. An atomic force microscope study revealed two mechanisms in the effect of anticancer drugs on rate-dependent young's Modulus of human prostate Cancer cells. PLoS One 10, e0126107.

Rianna, C., Kumar, P., Radmacher, M., 2018. The role of the microenvironment in the biophysics of cancer. Semin. Cell Dev. Biol. 73, 107-114.

Robey, R.W., Pluchino, K.M., Hall, M.D., Fojo, A.T., Bates, S.E., Gottesman, M.M., 2018. Revisiting the role of ABC transporters in multidrug-resistant cancer. Nat. Rev. Cancer 18, 452-464.

Røe, O.D., Szulkin, A., Anderssen, E., Flatberg, A., Sandeck, H., Amundsen, T., Erlandsen, S.E., Dobra, K., Sundstrøm, S.H., 2012. Molecular resistance fingerprint of pemetrexed and platinum in a long-term survivor of mesothelioma. PLoS One 7, e40521.

Rohnalter, V., Roth, K., Finkernagel, F., Adhikary, T., Obert, J., Dorzweiler, K., Bensberg, M., Müller-Brüsselbach, S., Müller, R., 2015. A multi-stage process including transient polyploidization and EMT precedes the emergence of chemoresistent ovarian carcinoma cells with a dedifferentiated and pro-inflammatory secretory phenotype. Oncotarget 6, 40005-40025.

Roisman, A., Castellano, G., Navarro, A., Gonzalez-Farre, B., Pérez-Galan, P., EsteveCodina, A., Dabad, M., Heath, S., Gut, M., Bosio, M., Bellot, P., Salembier, P. Oliveras, A., Slavutsky, I., Magnano, L., Horn, H., Rosenwald, A., Ott, G., Aymerich, M., López-Guillermo, A., Jares, P., Martín-Subero, J.I., Campo, E., Hernández, L., 2019. Differential expression of long non-coding RNAs are related to proliferation and histological diversity in follicular lymphomas. Br. J. Haematol. 184, 373-383.

Rosenbluth, M.J., Lam, W.A., Fletcher, D.A., 2006. Force microscopy of nonadherent cells: a comparison of leukemia cell deformability. Biophys. J. 90, 2994-3003.

Ruppen, J., Wildhaber, F.D., Strub, C., Hall, S.R.R., Schmid, R.A., Geiser, T., Guenat, O.T., 2015. Towards personalized medicine: chemosensitivity assays of patient lung cancer cell spheroids in a perfused microfluidic platform. Lab Chip 15, 3076-3085.

Sabhachandani, P., Motwani, V., Cohen, N., Sarkar, S., Torchilin, V., Konry, T., 2016. Generation and functional assessment of 3D multicellular spheroids in droplet based 
microfluidics platform. Lab Chip 16, 497-505

Sabhachandani, P., Sarkar, S., Mckenney, S., Ravi, D., Evens, A.M., Konry, T., 2019. Microfluidic assembly of hydrogel-based immunogenic tumor spheroids for evaluation of anticancer therapies and biomarker release. J. Control. Release 295, 21-30.

Saeinasab, M., Bahrami, A.R., González, J., Marchese, F.P., Martinez, D., Mowla, S.J., Matin, M.M., Huarte, M., 2019. SNHG15 is a bifunctional MYC-regulated noncoding locus encoding a lncRNA that promotes cell proliferation, invasion and drug resistance in colorectal cancer by interacting with AIF. J. Exp. Clin. Cancer Res. 38, 172.

Saidijam, M., Mahjub, H., Shabab, N., Yadegarazari, R., 2015. Simultaneous analysis of multidrug Re sistance 1(MDR1) C3435T, G2677T/A, and C1236T genotypes in Hamadan City Population, West of Iran. Iran. Biomed. J. 19, 57-62.

Sandoz, P.A., Tremblay, C., Equis, S., Pop, S., Pollaro, L., Cotte, Y., van der Goot, F.G., Frechin, M., 2018. Label free 3D analysis of organelles in living cells by refractive index shows pre-mitotic organelle spinning in mammalian stem cells. bioRxiv, 407239.

Sato, S., Rancourt, A., Sato, Y., Satoh, M.S., 2016. Single-cell lineage tracking analysis reveals that an established cell line comprises putative cancer stem cells and their heterogeneous progeny. Sci. Rep. 6, 23328.

Sato, S., Rancourt, A., Satoh, M.S., 2018. Identification of SNA-I-positive cells as stem-like cells in an established cell line using computerized single-cell lineage tracking. bioRxiv, 508705.

Schechter, R.B., Nagilla, M., Joseph, L., Reddy, P., Khattri, A., Watson, S., Locati, L.D., Licitra, L., Greco, A., Pelosi, G., Carcangiu, M.L., Lingen, M.W., Seiwert, T.Y., Cohen, E.E.W., 2015. Genetic profiling of advanced radioactive iodine-resistant differentiated thyroid cancer and correlation with axitinib efficacy. Cancer Lett. 359, 269-274.

Schröder, J., Maus, I., Meyer, K., Wördemann, S., Blom, J., Jaenicke, S., Schneider, J., Trost, E., Tauch, A., 2012. Complete genome sequence, lifestyle, and multi-drug resistance of the human pathogen Corynebacterium resistens DSM 45100 isolated from blood samples of a leukemia patient. BMC Genomics 13, 141.

Schroeder, T., 2011. Long-term single-cell imaging of mammalian stem cells. Nat. Methods 8, S30-5.

Seo, Y.H., Jo, Y., Oh, Y.J., Park, S., 2015. Nano-mechanical reinforcement in drug-resistant ovarian cancer cells. Biol. Pharm. Bull. 38, 389-395.

Shaffer, S.M., Dunagin, M.C., Torborg, S.R., Torre, E.A., Emert, B., Krepler, C., Beqiri, M., Sproesser, K., Brafford, P.A., Xiao, M., Eggan, E., Anastopoulos, I.N., Vargas-Garcia, C.A., Singh, A., Nathanson, K.L., Herlyn, M., Raj, A., 2017. Rare cell variability and drug-induced reprogramming as a mode of cancer drug resistance. Nature 546, 431-435.

Shang, M., Soon, R.H., Lim, C.T., Khoo, B.L., Han, J., 2019. Microfluidic modelling of the tumor microenvironment for anti-cancer drug development. Lab Chip 19, 369-386.

Sharma, S., LeClaire, M., Gimzewski, J.K., 2018. Ascent of atomic force microscopy as a nanoanalytical tool for exosomes and other extracellular vesicles. Nanotechnology 29, 132001.

Sharma, S., Santiskulvong, C., Bentolila, L.A., Rao, J., Dorigo, O., Gimzewski, J.K., 2012. Correlative nanomechanical profiling with super-resolution F-actin imaging reveals novel insights into mechanisms of cisplatin resistance in ovarian cancer cells. Nanomedicine 8, 757-766.

Shell, S., Park, S.-M., Radjabi, A.R., Schickel, R., Kistner, E.O., Jewell, D.A., Feig, C., Lengyel, E., Peter, M.E., 2007. Let-7 expression defines two differentiation stages of cancer. Proc. Natl. Acad. Sci. U. S. A. 104, 11400-11405.

Siddiqui, L., Mishra, H., Mishra, P.K., Iqbal, Z., Talegaonkar, S., 2018. Novel 4-in-1 strategy to combat colon cancer, drug resistance and cancer relapse utilizing functionalized bioinspiring lignin nanoparticle. Med. Hypotheses 121, 10-14.

Sinha, A., Huang, V., Livingstone, J., Wang, J., Fox, N.S., Kurganovs, N., Ignatchenko, V., Fritsch, K., Donmez, N., Heisler, L.E., Shiah, Y.-J., Yao, C.Q., Alfaro, J.A., Volik, S., Lapuk, A., Fraser, M., Kron, K., Murison, A., Lupien, M., Sahinalp, C., Collins, C.C., Tetu, B., Masoomian, M., Berman, D.M., van der Kwast, T., Bristow, R.G., Kislinger, T., Boutros, P.C., 2019. The proteogenomic landscape of curable prostate Cancer. Cancer Cell 35, 414-427 e6.

Sleeboom, J.J.F., Eslami Amirabadi, H., Nair, P., Sahlgren, C.M., den Toonder, J.M.J., 2018. Metastasis in context: modeling the tumor microenvironment with cancer-on-achip approaches. Dis. Model. Mech. 11 pii: dmm033100.

Soares, F.B., Camargo, C.H., Cunha, M.P.V., de Almeida, E.A., Bertani, A.M., de, J., de Carvalho, E., de Paiva, J.B., Fernandes, S.A., Tiba-Casas, M.R., 2019. Subtyping of plasmid-mediated quinolone resistance among Salmonella serotypes by whole genome sequencing. Diagn. Microbiol. Infect. Dis. 94, 403-406.

Sobrino, A., Phan, D.T.T., Datta, R., Wang, X., Hachey, S.J., Romero-López, M., Gratton, E., Lee, A.P., George, S.C., Hughes, C.C.W., 2016. 3D microtumors in vitro supported by perfused vascular networks. Sci. Rep. 6, 31589.

Solon, J., Levental, I., Sengupta, K., Georges, P.C., Janmey, P.A., 2007. Fibroblast adaptation and stiffness matching to Soft elastic substrates. Biophys. J. 93, 4453-4461.

Somaweera, H., Ibraguimov, A., Pappas, D., 2016. A review of chemical gradient systems for cell analysis. Anal. Chim. Acta 907, 7-17.

Sontheimer-Phelps, A., Hassell, B.A., Ingber, D.E., 2019. Modelling cancer in microfluidic human organs-on-chips. Nat. Rev. Cancer 19, 65-81.

Soukupova, J., Zemankova, P., Lhotova, K., Janatova, M., Borecka, M., Stolarova, L., Lhota, F., Foretova, L., Machackova, E., Stranecky, V., Tavandzis, S., Kleiblova, P., Vocka, M., Hartmannova, H., Hodanova, K., Kmoch, S., Kleibl, Z., 2018. Validation of CZECANCA (CZEch CAncer paNel for Clinical Application) for targeted NGS-based analysis of hereditary cancer syndromes. PLoS One 13, e0195761.

Stadler, T., Skylaki, S.D., Kokkaliaris, K., Schroeder, T., 2018. On the statistical analysis of single cell lineage trees. J. Theor. Biol. 439, 160-165.

Starodubtseva, M., Starodubtsev, I.E., Yegorenkov, N.I., Kuzhel, N.S., Konstantinova, E.E., Chizhik, S.A., 2017a. Physical-mechanical image of the cell surface on the base of
AFM data in contact mode. IOP Conf. Ser. Mater. Sci. Eng. 256, 012016.

Starodubtseva, M.N., Mitsura, E.F., Starodubtsev, I.E., Chelnokova, I.A., Yegorenkov, N.I., Volkova, L.I., Kharin, Y.S., 2019. Nano- and microscale mechanical properties of erythrocytes in hereditary spherocytosis. J. Biomech. 83, 1-8.

Starodubtseva, M.N., Starodubtsev, I.E., Starodubtsev, E.G., 2017b. Novel fractal characteristic of atomic force microscopy images. Micron 96, 96-102.

Stylianou, A., Lekka, M., Stylianopoulos, T., 2018. AFM assessing of nanomechanical fingerprints for cancer early diagnosis and classification: from single cell to tissue level. Nanoscale 10, 20930-20945.

Sun, J., Yuan, X., Li, X., Wang, D., Shan, T., Wang, W., Wan, Q., Wang, X., Yan, J., Gao, S., 2017. Comparative transcriptome analysis of the global circular RNAs expression profiles between SHEE and SHEEC cell lines. Am. J. Transl. Res. 9, 5169.

Sundaresan, T.K., Sequist, L.V., Heymach, J.V., Riely, G.J., Jänne, P.A., Koch, W.H., Sullivan, J.P., Fox, D.B., Maher, R., Muzikansky, A., Webb, A., Tran, H.T., Giri, U., Fleisher, M., Yu, H.A., Wei, W., Johnson, B.E., Barber, T.A., Walsh, J.R., Engelman, J.A., Stott, S.L., Kapur, R., Maheswaran, S., Toner, M., Haber, D.A., 2016. Detection of T790M, the acquired resistance EGFR mutation, by tumor biopsy versus noninvasive blood-based analyses. Clin. Cancer Res. 22, 1103-1110.

Szankasi, P., Schumacher, J.A., Kelley, T.W., 2016. Detection of BCR-ABL1 mutations that confer tyrosine kinase inhibitor resistance using massively parallel, next generation sequencing. Ann. Hematol. 95, 201-210.

Taniguchi, K., Karin, M., 2018. NF-kB, inflammation, immunity and cancer: coming of age. Nat. Rev. Immunol. 18, 309-324.

Teixeira, V.H., Pipinikas, C.P., Pennycuick, A., Lee-Six, H., Chandrasekharan, D., Beane, J., Morris, T.J., Karpathakis, A., Feber, A., Breeze, C.E., Ntolios, P., Hynds, R.E. Falzon, M., Capitanio, A., Carroll, B., Durrenberger, P.F., Hardavella, G., Brown, J.M., Lynch, A.G., Farmery, H., Paul, D.S., Chambers, R.C., McGranahan, N., Navani, N., Thakrar, R.M., Swanton, C., Beck, S., George, P.J., Spira, A., Campbell, P.J., Thirlwell, C., Janes, S.M., 2019. Deciphering the genomic, epigenomic, and transcriptomic landscapes of pre-invasive lung cancer lesions. Nat. Med. 25, 517-525.

Tellez-Gabriel, M., Ory, B., Lamoureux, F., Heymann, M.-F., Heymann, D., 2016. Tumour heterogeneity: the key advantages of single-cell analysis. Int. J. Mol. Sci. 17, E2142.

Thomson, E., Ip, C.L.C., Badhan, A., Christiansen, M.T., Adamson, W., Ansari, M.A., Bibby, D., Breuer, J., Brown, A., Bowden, R., Bryant, J., Bonsall, D., Da Silva Filipe, A., Hinds, C., Hudson, E., Klenerman, P., Lythgow, K., Mbisa, J.L., McLauchlan, J., Myers, R., Piazza, P., Roy, S., Trebes, A., Sreenu, V.B., Witteveldt, J., Barnes, E., Simmonds, P., Simmonds, P., 2016. Comparison of next-generation sequencing technologies for comprehensive assessment of full-length hepatitis C viral genomes. J. Clin. Microbiol. 54, 2470-2484.

Tinevez, J.-Y., Perry, N., Schindelin, J., Hoopes, G.M., Reynolds, G.D., Laplantine, E., Bednarek, S.Y., Shorte, S.L., Eliceiri, K.W., 2017. TrackMate: an open and extensible platform for single-particle tracking. Methods 115, 80-90.

Todoric, J., Karin, M., 2019. The fire within: cell-autonomous mechanisms in inflammation-driven Cancer. Cancer Cell 35, 714-720.

Tomar, D., Yadav, A.S., Kumar, D., Bhadauriya, G., Kundu, G.C., 2019. Non-coding RNAs as potential therapeutic targets in breast cancer. Biochim. Biophys. Acta Gene Regul. Mech S1874-9399(19)30016-1.

Traenkle, B., Rothbauer, U., 2017. Under the microscope: single-domain antibodies for live-cell imaging and super-resolution microscopy. Front. Immunol. 8, 1030.

Turajlic, S., Sottoriva, A., Graham, T., Swanton, C., 2019. Resolving genetic heterogeneity in cancer. Nat. Rev. Genet. 20, 404-416.

Uhl, C.G., Liu, Y., 2019. Microfluidic device for expedited tumor growth towards drug evaluation. Lab Chip 19, 1458-1470.

Ulrich, T.A., de Juan Pardo, E.M., Kumar, S., 2009. The mechanical rigidity of the extracellular matrix regulates the structure, motility, and proliferation of glioma cells. Cancer Res. 69, 4167-4174.

Valente, K.P., Khetani, S., Kolahchi, A.R., Sanati-Nezhad, A., Suleman, A., Akbari, M., 2017. Microfluidic technologies for anticancer drug studies. Drug Discov. Today 22, 1654-1670.

Venkatesan, P., Das, S., Krishnan, M.M.R., Chakraborty, C., Chaudhury, K., Mandal, M., 2010. Effect of AEE788 and/or Celecoxib on colon cancer cell morphology using advanced microscopic techniques. Micron 41, 247-256.

Verma, R., Sharma, P.C., 2018. Next generation sequencing-based emerging trends in molecular biology of gastric cancer. Am. J. Cancer Res. 8, 207-225.

Vitale, I., Sistigu, A., Manic, G., Rudqvist, N.-P., Trajanoski, Z., Galluzzi, L., 2019. Mutational and antigenic landscape in tumor progression and cancer immunotherapy. Trends Cell Biol. 29, 396-416.

Wakai, T., Prasoon, P., Hirose, Y., Shimada, Y., Ichikawa, H., Nagahashi, M., 2019. Nextgeneration sequencing-based clinical sequencing: toward precision medicine in solid tumors. Int. J. Clin. Oncol. 24, 115-122.

Walerych, D., Lisek, K., Sommaggio, R., Piazza, S., Ciani, Y., Dalla, E., Rajkowska, K., Gaweda-Walerych, K., Ingallina, E., Tonelli, C., Morelli, M.J., Amato, A., Eterno, V., Zambelli, A., Rosato, A., Amati, B., Wiśniewski, J.R., Del Sal, G., 2016. Proteasome machinery is instrumental in a common gain-of-function program of the p53 missense mutants in cancer. Nat. Cell Biol. 18, 897-909.

Wang, J., Dean, D.C., Hornicek, F.J., Shi, H., Duan, Z., 2019a. RNA sequencing (RNA-Seq) and its application in ovarian cancer. Gynecol. Oncol. 152, 194-201.

Wang, J., Wan, Z., Liu, W., Li, L., Ren, Li, Wang, X., Sun, P., Ren, Lili, Zhao, H., Tu, Q. Zhang, Z., Song, N., Zhang, L., 2009a. Atomic force microscope study of tumor cell membranes following treatment with anti-cancer drugs. Biosens. Bioelectron. 25, 721-727.

Wang, Q., Zhang, W., Hao, S., 2017. LncRNA CCAT1 modulates the sensitivity of paclitaxel in nasopharynx cancers cells via miR-181a/CPEB2 axis. Cell Cycle 16, 795-801.

Wang, S., Mao, S., Li, M., Li, H.F., Lin, J.M., 2019b. Near-physiological microenvironment simulation on chip to evaluate drug resistance of different loci in tumour mass. Talanta 191, 67-73. 
Wang, Z., Gerstein, M., Snyder, M., 2009b. RNA-Seq: a revolutionary tool for transcriptomics. Nat. Rev. Genet. 10, 57-63.

Wolf, K., Mazo, I., Leung, H., Engelke, K., von Andrian, U.H., Deryugina, E.I., Strongin, A.Y., Bröcker, E.-B., Friedl, P., 2003. Compensation mechanism in tumor cell migration. J. Cell Biol. 160, 267-277.

Worm, J., Guldberg, P., 2002. DNA methylation: an epigenetic pathway to cancer and a promising target for anticancer therapy. J. Oral Pathol. Med. 31, 443-449.

Wu, Q., Yang, Z., Xia, L., Nie, Y., Wu, K., Shi, Y., Fan, D., 2014. Methylation of miR-129$5 p$ CpG island modulates multi-drug resistance in gastric cancer by targeting $\mathrm{ABC}$ transporters. Oncotarget 5, 11552-11563.

Wu, S., Liu, X., Zhou, X., Liang, X.M., Gao, D., Liu, H., Zhao, G., Zhang, Q., Wu, X., 2016. Quantification of cell viability and rapid screening anti-cancer drug utilizing nanomechanical fluctuation. Biosens. Bioelectron. 77, 164-173.

Wu, Y., Wang, H., 2018. LncRNA NEAT1 promotes dexamethasone resistance in multiple myeloma by targeting miR-193a/MCL1 pathway. J. Biochem. Mol. Toxicol. 32, e22008.

Xi, X., Li, T., Huang, Y., Sun, J., Zhu, Y., Yang, Y., Lu, Z.J., 2017. RNA biomarkers: frontier of precision medicine for cancer. Noncoding RNA 3, E9.

Xiao, J., Niu, S., Zhu, J., Lv, L., Deng, H., Pan, D., Shen, D., Xu, C., Shen, Z., Tao, T., 2018. miR-22-3p enhances multi-chemoresistance by targeting NET1 in bladder cancer cells. Oncol. Rep. 39, 2731-2740.

Xiao, L., Tang, M., Lia, Q., Zhou, A., 2013. Non-invasive detection of biomechanical and biochemical responses of human lung cells to short time chemotherapy exposure using AFM and confocal Raman spectroscopy. Anal. Methods 5, 874-879.

Xu, J., Wu, J., Fu, C., Teng, F., Liu, S., Dai, C., Shen, R., Jia, X., 2018. Multidrug resistant lncRNA profile in chemotherapeutic sensitive and resistant ovarian cancer cells. J. Cell. Physiol. 233, 5034-5043.

Xu, K., Liang, X., Shen, K., Sun, L., Cui, D., Zhao, Y., Tian, J., Ni, L., Liu, J., 2012. MiR-222 modulates multidrug resistance in human colorectal carcinoma by down-regulating ADAM-17. Exp. Cell Res. 318, 2168-2177.

Xu, Z., Li, E., Guo, Z., Yu, R., Hao, H., Xu, Y., Sun, Z., Li, X., Lyu, J., Wang, Q., 2016. Design and construction of a multi-organ microfluidic chip mimicking the in vivo microenvironment of lung cancer metastasis. ACS Appl. Mater. Interfaces 8, $25840-25847$.

Yamamoto, T., Kosaka, N., Ochiya, T., 2019. Latest advances in extracellular vesicles: from bench to bedside. Sci. Technol. Adv. Mater. 20, 746-757.

Yang, X., Li, K., Zhang, X., Liu, C., Guo, B., Wen, W., Gao, X., 2018. Nanofiber membrane supported lung-on-a-chip microdevice for anti-cancer drug testing. Lab Chip 18 486-495.

Yang, X., Zhuo, M., Ye, X., Bai, H., Wang, Z., Sun, Y., Zhao, J., An, T., Duan, J., Wu, M., Wang, J., 2016. Quantification of mutant alleles in circulating tumor DNA can predict survival in lung cancer. Oncotarget 7, 20810-20824.

Yildiz-Ozturk, E., Gulce-Iz, S., Anil, M., Yesil-Celiktas, O., 2017. Cytotoxic responses of carnosic acid and doxorubicin on breast cancer cells in butterfly-shaped microchips in comparison to 2D and 3D culture. Cytotechnology 69, 337-347.

Yu, C.-Y., Kuo, H.-C., 2019. The emerging roles and functions of circular RNAs and their generation. J. Biomed. Sci. 26, 29.

Zhang, G., Long, M., Wu, Z.-Z., Yu, W.-Q., 2002. Mechanical properties of hepatocellular carcinoma cells. World J. Gastroenterol. 8, 243-246.

Zhao, H., Huang, Y., Shi, J., Dai, Y., Wu, L., Zhou, H., 2018. ABCC10 plays a significant role in the transport of Gefitinib and contributes to acquired resistance to gefitinib in NSCLC. Front. Pharmacol. 9, 1312.

Zhitomirsky, B., Assaraf, Y.G., 2015. Lysosomal sequestration of hydrophobic weak base chemotherapeutics triggers lysosomal biogenesis and lysosome-dependent cancer multidrug resistance. Oncotarget 6, 1143-1156.

Zhitomirsky, B., Assaraf, Y.G., 2016. Lysosomes as mediators of drug resistance in cancer. Drug Resist. Updat. 24, 23-33.

Zhitomirsky, B., Assaraf, Y.G., 2017. Lysosomal accumulation of anticancer drugs triggers lysosomal exocytosis. Oncotarget 8, 45117-45132.

Zhong, Q., Inniss, D., Kjoller, K., Elings, V.B., 1993. Fractured polymer/silica fiber surface studied by tapping mode atomic force microscopy. Surf. Sci. Lett. 290, L688-L692.

Zuchowska, A., Kwapiszewska, K., Chudy, M., Dybko, A., Brzozka, Z., 2017. Studies of anticancer drug cytotoxicity based on long-term HepG2 spheroid culture in a microfluidic system. Electrophoresis 38, 1206-1216. 